\title{
Impaired Short-Term Plasticity in Mossy Fiber Synapses Caused by Mitochondrial Dysfunction of Dentate Granule Cells Is the Earliest Synaptic Deficit in a Mouse Model of Alzheimer's Disease
}

\author{
Sang Hun Lee, ${ }^{1,3 *}$ Kyung-Ran Kim, ${ }^{1,3 *}$ Shin-Young Ryu, ${ }^{1}$ Sungmin Son, ${ }^{2,3}$ Hyun Seok Hong, ${ }^{2,3}$ Inhee Mook-Jung, ${ }^{2,3}$ \\ Suk-Ho Lee, ${ }^{1}$ and Won-Kyung Ho ${ }^{1,3}$ \\ ${ }^{1}$ Cell Physiology Laboratory, Department of Physiology and bioMembrane Plasticity Research Center, ${ }^{2}$ Department of Biochemistry and Biomedical \\ Sciences, and ${ }^{3}$ The World Class University Neurocytomics Program, Seoul National University College of Medicine, Seoul 110-799, Republic of Korea
}

\begin{abstract}
Alzheimer's disease (AD) in the early stages is characterized by memory impairment, which may be attributable to synaptic dysfunction. Oxidative stress, mitochondrial dysfunction, and $\mathrm{Ca}^{2+}$ dysregulation are key factors in the pathogenesis of $\mathrm{AD}$, but the causal relationship between these factors and synaptic dysfunction is not clearly understood. We found that in the hippocampus of an AD mouse model (Tg2576), mitochondrial $\mathrm{Ca}^{2+}$ handling in dentate granule cells was impaired as early as the second postnatal month, and this $\mathrm{Ca}^{2+}$ dysregulation caused an impairment of post-tetanic potentiation in mossy fiber-CA3 synapses. The alteration of cellular $\mathrm{Ca}^{2+} \mathrm{clearance}$ in Tg2576 mice is region-specific within hippocampus because in another region, CA1 pyramidal neuron, no significant difference in $\mathrm{Ca}^{2+}$ clearance was detected between wild-type and Tg2576 mice at this early stage. Impairment of mitochondrial $\mathrm{Ca}^{2+}$ uptake was associated with increased mitochondrial reactive oxygen species and depolarization of mitochondrial membrane potential. Mitochondrial dysfunctions in dentate granule cells and impairment of post-tetanic potentiation in mossy fiber-CA3 synapses were fully restored when brain slices obtained from $\mathrm{Tg} 2576$ were pretreated with antioxidant, suggesting that mitochondrial oxidative stress initiates other dysfunctions. Reversibility of early dysfunctions by antioxidants at the preclinical stage of AD highlights the importance of early diagnosis and antioxidant therapy to delay or prevent the disease processes.
\end{abstract}

\section{Introduction}

Alzheimer's disease $(\mathrm{AD})$ is the most common neurodegenerative disease, characterized by progressive memory impairment and accumulation of extracellular amyloid plaques along with intraneuronal neurofibrillary tangles. Since the earliest clinical symptom characteristic of AD is a pure impairment of memory, it has been proposed that $\mathrm{AD}$ begins with subtle alteration of hippocampal synaptic efficacy before frank neuronal degeneration (Selkoe, 2002). Cellular dysfunctions such as mitochondrial dysfunction (Du et al., 2008; Moreira et al., 2010), increased oxidative stress (Smith et al., 1996; Beal, 2005), and dysregulation of

Received Jan. 31, 2012; accepted March 1, 2012.

Author contributions: S.-Y.R., I.M.-J., S.-H.L., and W.-K.H. designed research; S.H.L., K.-R.K., S.S., and H.S.H. performed research; S.H.L., K.-R.K., S.-Y.R., I.M.-J., S.-H.L., and W.-K.H. analyzed data; S.-Y.R., S.-H.L., and W.-K.H. wrote the paper.

This work was supported by the World Class University Neurocytomics Program (R32-10084) and the Science Research Center Program (2010-0029394) from the Korean Ministry of Education, Science and Technology.

*S.H.L. and K.-R.K. contributed equally to this work.

The authors declare no competing financial interests.

Correspondence should be addressed to either of the following: Dr. Won-Kyung Ho, Department of Physiology, Seoul National University College of Medicine, 103 Daehak-ro, Jongno-gu, Seoul 110-799, Republic of Korea, E-mail: wonkyung@snu.ac.kr; or Dr. Suk-Ho Lee, Department of Physiology, Seoul National University College of Medicine, 103 Daehak-ro, Jongno-gu, Seoul 110-799, Republic of Korea, E-mail: leesukho@snu.ac.kr.

DOI:10.1523/JNEUROSCI.0465-12.2012

Copyright $\odot 2012$ the authors $\quad 0270-6474 / 12 / 325953-11 \$ 15.00 / 0$
$\mathrm{Ca}^{2+}$ homeostasis (Tu et al., 2006; Bezprozvanny and Mattson, 2008) are associated with the pathogenesis of AD. Despite numerous studies, it is still elusive which is, indeed, the earliest cellular event causing subsequent neuronal dysfunctions specific to $\mathrm{AD}$. To gain mechanistic insight into the pathogenesis of $\mathrm{AD}$ and to develop therapeutic strategies for preventing disease progression, it is critical to investigate early functional changes at the preclinical, and possibly reversible, stage of the disease.

The amyloid $\beta$ protein $(\mathrm{A} \beta)$ is believed to be a common initiating factor in AD (Hardy and Selkoe, 2002; Tanzi and Bertram, 2005). The relationship between $\mathrm{A} \beta$ and $\mathrm{Ca}^{2+}$ dysregulation has been widely investigated (Mattson et al., 1992; Demuro et al., 2005), but it is still unclear whether overproduction of $\mathrm{A} \beta$ in vivo can indeed cause $\mathrm{Ca}^{2+}$ dysregulation, and if so, what the mechanism is. Most of the previous studies mainly focused on the mechanisms of $\mathrm{Ca}^{2+}$ overload leading to cell death, but failed to uncover $\mathrm{AD}$-specific features of the $\mathrm{Ca}^{2+}$ dysregulation. Considering that $\mathrm{Ca}^{2+}$ homeostasis is achieved by the balance between the multitude of $\mathrm{Ca}^{2+}$ influx/releasing mechanisms $\left(\mathrm{Ca}^{2+}\right.$ channels) and $\mathrm{Ca}^{2+}$ clearance mechanisms (pumps and exchangers), a careful quantitative analysis of each mechanism is necessary to identify subtle alterations that may occur at the early stage of AD pathogenesis. More importantly, $\mathrm{A} \beta$ is also known to cause various forms of synaptic dysfunction (Walsh et al., 2002; Palop et 
al., 2007; Shankar et al., 2008; He et al., 2009; Witton et al., 2010), but causal relationship between $\mathrm{A} \beta$-induced synaptic dysfunction and $\mathrm{Ca}^{2+}$ dysregulation is not clearly understood.

Here, using an amyloid precursor protein (APP) transgenic mouse model ( $\mathrm{Tg} 2576)$ at the age of 1-2 months, we investigated the $\mathrm{Ca}^{2+}$ dynamics of hippocampal neurons and discovered that a selective impairment of mitochondrial $\mathrm{Ca}^{2+}$ uptake in dentate granule cells (GCs) is the earliest sign of $\mathrm{Ca}^{2+}$ dysregulation. We also demonstrate that the impaired mitochondrial $\mathrm{Ca}^{2+}$ handling is attributable to mitochondrial dysfunction that involves increased reactive oxygen species (ROS) production, and this leads to the impairment of short-term plasticity in the mossy fiber-CA3 synapse. Furthermore, antioxidant pretreatment effectively restored synaptic plasticity as well as mitochondrial $\mathrm{Ca}^{2+}$ handling. Our data provide the first evidence of a causal link between mitochondrial dysfunction and impaired synaptic plasticity in $\mathrm{AD}$ pathogenesis at the early preclinical stage.

\section{Materials and Methods}

Preparation of brain slices. Brain slices were prepared from male Tg2576 transgenic mice and their littermate wild-type control mice aged from 1 to 2 months old. Mice were killed by decapitation after being anesthetized with pentobarbital sodium, and the whole brain was immediately removed from the skull and chilled in artificial CSF at $4^{\circ} \mathrm{C}$. Transverse hippocampal slices (300 $\mu \mathrm{m}$ thick) were prepared using a vibratome (VT1200S, Leica). For functional studies, slices were incubated at $35^{\circ} \mathrm{C}$ for $30 \mathrm{~min}$ and thereafter maintained at $32^{\circ} \mathrm{C}$ until in situ slice patch recordings and fluorescence microscopy. Hippocampal granule cells of dentate gyrus were visualized using an upright microscope equipped with differential interference contrast (DIC) optics (BX51WI, Olympus). All experiments procedures were conducted in accordance with the guidelines of the University Committee on Animal Resource in Seoul National University (Approval No. SNU-090115-7).

Preparation of oligomeric $A \beta_{1-42}$ and $A \beta_{1-40}$. Oligomeric $\mathrm{A} \beta_{1-42}$ and $\mathrm{A} \beta_{1-40}$ were prepared as previously described (Hong et al., 2009). To prepare the oligomer, $\mathrm{A} \beta_{1-42}$ or $\mathrm{A} \beta_{1-40}$ peptides were incubated with PBS at $4^{\circ} \mathrm{C}$ for $24 \mathrm{~h}$. The resulting oligomers were verified by atomic force microscopy (AFM, PARK Systems) as previously described (Maezawa et al., 2006). For AFM analysis, peptide solutions were aliquoted and immediately spotted onto freshly cleaved micas. The micas were rinsed with water twice and dried in the air. AFM images were examined to characterize the size of oligomeric $\mathrm{A} \beta$. It showed globular aggregate structures between 5 and $15 \mathrm{~nm}$ in size.

Measurement of $A \beta$ content. Extracts from different brain regions were measured by a sandwich ELISA as described previously (Cho et al., 2009). Briefly, cortical region, dentate gyrus (DG), and hippocampus without dentate gyrus [Hippo(-DG)] were lysed by sonication in $70 \%$ formic acid solution. After centrifugation, formic acid-extracts were neutralized initially by 1:20 dilution into $1 \mathrm{M}$ Tris phosphate buffer, $\mathrm{pH} 11$, and then diluted as necessary in EIA buffer (1\% BSA, $0.05 \%$ Tween 20 in PBS). A $\beta$ levels were measured by a sandwich ELISA kit using an anti-A $\beta_{1-40}$ or $-\mathrm{A} \beta_{1-42}$ antibody, according to the manufacturer's instructions (Immuno-Biological Laboratories). Using the wet weight of brain in the original homogenate, the final values of $A \beta$ in the brain were expressed as nanogram per milligram wet weight.

Electrophysiological recordings. Whole-cell patch-clamp techniques were used for introducing $\mathrm{Ca}^{2+}$-indicator dye into the soma of hippocampal neurons and also for applying depolarizing pulses. The pipette solution contained the following (in $\mathrm{mm}$ ): $143 \mathrm{~K}$-gluconate, $7 \mathrm{KCl}, 15$ HEPES, 4 MgATP, 0.3 NaGTP, 4 Na-ascorbate, and 0.1 EGTA/or Fura-2 pentapotassium salt with the $\mathrm{pH}$ adjusted to 7.3 with $\mathrm{KOH}$. The bath solution (or aCSF) for the control experiments contained the following (in mM): $125 \mathrm{NaCl}, 25 \mathrm{NaHCO}_{3}, 2.5 \mathrm{KCl}, 1.25 \mathrm{NaH}_{2} \mathrm{PO}_{4}, 2 \mathrm{CaCl}_{2}, 1$ $\mathrm{MgCl}_{2}, 20$ glucose, 1.2 pyruvate, and $0.4 \mathrm{Na}$-ascorbate, $\mathrm{pH} 7.4$ when saturated with carbogen $\left(95 \% \mathrm{O}_{2}\right.$ and $\left.5 \% \mathrm{CO}_{2}\right)$. The superfusion rate of bathing solution and the volume of the recording chamber for slices were
$2.2 \mathrm{ml} / \mathrm{min}$ and $1.2 \mathrm{ml}$, respectively. Patch pipettes with a tip resistance of 5-6 $\mathrm{M} \Omega$ were used. The series resistance $\left(R_{\mathrm{s}}\right)$ after establishing wholecell configuration was between 10 and $15 \mathrm{M} \Omega$. Electrophysiological recordings were made in somata with EPC-8 amplifier (HEKA). Experiments were performed at $32 \pm 1^{\circ} \mathrm{C}$. All chemicals were obtained from Sigma, except Fura-2 pentapotassium salt and MitoSOX Red (Invitrogen). EPSCs at mossy fiber (MF) synapses were recorded from CA3 pyramidal cells (CA3-PCs) in a whole-cell mode at a holding potential of $-60 \mathrm{mV}$. Patch pipettes (2-4 M $\Omega$ ) were filled with an internal solution containing the following (in $\mathrm{mm}$ ): $143 \mathrm{~K}$-gluconate, $7 \mathrm{KCl}$, 15 HEPES, 4 MgATP, 0.3 NaGTP, and $4 \mathrm{Na}$-ascorbate, 0.1 EGTA at pH 7.3 (adjusted with $\mathrm{KOH})$. Synaptic responses were evoked by extracellular stimulation (100 $\mu$ s duration; $10-25 \mu \mathrm{A}$ ) via a stimulator (Stimulus Isolator A360; WPI) connected to a patch electrode filled with aCSF solution, and placed in stratum lucidum of CA3 field. The stimulus intensity was adjusted such that EPSC amplitude is in the range between $100 \mathrm{pA}$ and 300 pA. After 10-15 min of stabilization from the break-in, EPSCs were recorded initially by $0.2 \mathrm{~Hz}$ stimulation for 3-5 min followed by highfrequency stimulation (HFS; $25 \mathrm{~Hz}, 5 \mathrm{~s}$ ) to induce a post-tetanic potentiation (PTP). EPSC recordings with $<20 \%$ series resistance change were included for data analysis. At the end of each experiment, we examined the effect of $2 \mu \mathrm{M}$ DCG4, a group II mGluR agonist, to confirm that we had studied MF synapses.

Cytosolic $\mathrm{Ca}^{2+}$ measurements. The procedures for cytosolic $\mathrm{Ca}^{2+}$ measurement in slices have been previously described in detail (Lee et al., 2007, 2009). Briefly, we measured $\left[\mathrm{Ca}^{2+}\right]_{\mathrm{i}}$ in somata of hippocampal GCs and CA1 PCs using Fura-2 pentapotassium salt introduced by a patch pipette. Fluorescence imaging was performed with a $60 \times$ waterimmersion objective (NA 0.9, LUMPlanFl, Olympus), an air-cooled slow-scan CCD camera (SensiCam, PCO) and a monochromator (Polychrome-IV, TILL-Photonics), which were controlled by a personal computer and ITC-18, running a custom-made software programmed with Microsoft Visual C++ (version 6.0; CCDLabo1.2). To increase the time resolution and minimize photo-bleaching, we adopted the single-wavelength protocol for $\mathrm{Ca}^{2+}$-imaging of the slices. Images were taken at $20 \mathrm{~Hz}$ with single wavelength excitation at $380 \mathrm{~nm}$ $\left(F_{380}\right)$. The isosbestic fluorescence values $\left(F_{\text {iso }}\right)$ at $360 \mathrm{~nm}$ were linearly interpolated between points just before and after the period of excitation at $380 \mathrm{~nm}$. The ratio $r=F_{\text {iso }} / F_{380}$ was converted to $\left[\mathrm{Ca}^{2+}\right]$ values using the following equation:

$$
\left[\mathrm{Ca}^{2+}\right]=K_{\mathrm{eff}} \cdot \frac{R-R_{\min }}{R_{\max }-R}
$$

Calibration parameters were determined using the in-cell calibration method. $R_{\min }$ and $R_{\max }$ were measured in the somata of granule cells which were intracellularly perfused with a pipette solution containing 10 mM BAPTA or $10 \mathrm{~mm} \mathrm{CaCl}_{2}$, respectively. The ratio at intermediate $\left[\mathrm{Ca}^{2+}\right]_{\mathrm{i}}$ was measured using a pipette solution containing $10 \mathrm{~mm}$ BAPTA and $5 \mathrm{mM} \mathrm{CaCl}_{2}\left(\left[\mathrm{Ca}^{2+}\right]_{\mathrm{i}} \approx 216 \mathrm{nM}\right)$. The effective dissociation constant of fura-2 $\left(K_{\text {eff }}\right)$ was calculated by measuring the fluorescence ratio at the intermediate $\left[\mathrm{Ca}^{2+}\right]_{\mathrm{i}}$ and by rearranging Equation 1 for $K_{\text {eff }}$. Typical values for $R_{\min }, R_{\max }$, and $K_{\text {eff }}$ were $0.89,4.86$, and $1.48 \mu \mathrm{M}$, respectively.

Calculation of the $\mathrm{Ca}^{2+}$ decay rate constant from a biexponential function. We estimated the calcium clearance of a cell from the decay phase of $\mathrm{Ca}^{2+}$ transients (CaTs; Lee et al., 2009). The CaTs recorded in the somata of the GCs were best fitted with a biexponential function:

$$
\left[\mathrm{Ca}^{2+}\right](t)=A_{0}+A_{1} \cdot \exp \left(-r_{1} \cdot t\right)+A_{1} \cdot \exp \left(-r_{2} \cdot t\right)
$$

The $\mathrm{Ca}^{2+}$-decay rate at the peak $\left(d\left[\mathrm{Ca}^{2+}\right](t) /\left.d t\right|_{t=0}\right.$, denoted by $\left.r_{t=0}\right)$ of the CaT which is fitted with Equation 2 can be estimated from the following equation:

$$
r_{t=0}=A_{1} \cdot r_{1}+A_{2} \cdot r_{2}
$$

Because $r_{t=0}$ highly depends on the amplitude of $\operatorname{CaTs}\left(\Delta\left[\mathrm{Ca}^{2+}\right]_{\text {peak }}\right)$, it cannot be used as a parameter for statistical comparison of the $\mathrm{Ca}^{2+}$ clearance between two CaTs with different peak amplitudes. Therefore, 


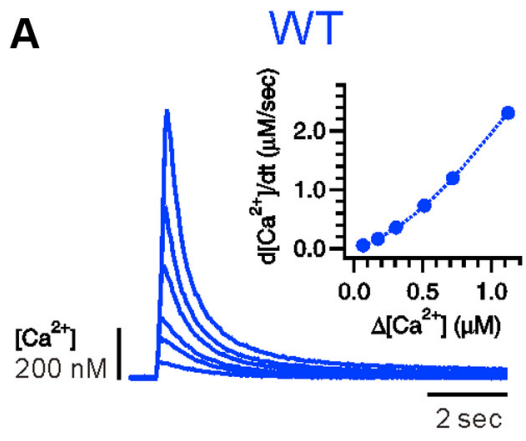

B

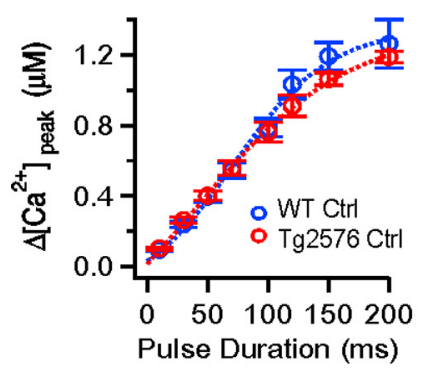

C

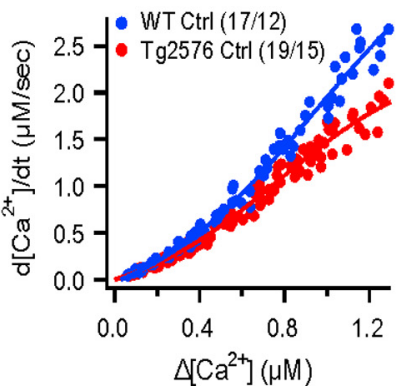

Tg2576

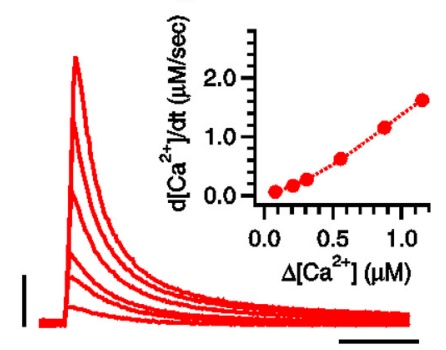

D

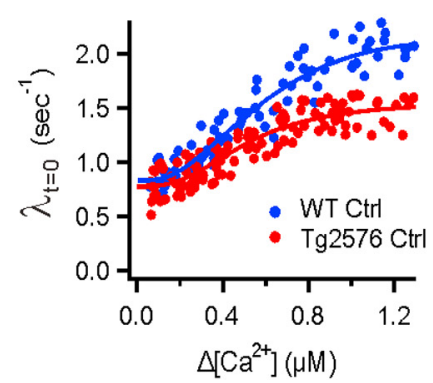

E

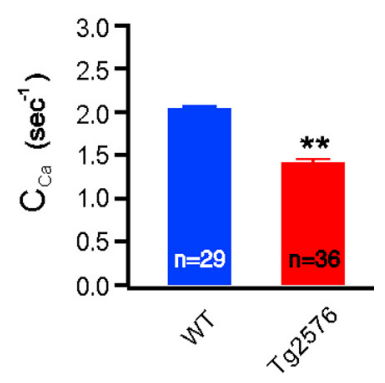

Figure 1. $\quad \mathrm{Ca}^{2+}$ clearance in the granule cells of the wild-type and Tg2576 mice. $A$, Representative CaTs in the soma of a GC of the hippocampal dentate gyrus from wild-type (WT, blue) and $\operatorname{Tg} 2576$ (red) mice. CaTs were evoked by a depolarizing step pulse of various durations $(10,30,50,100,150$, and $200 \mathrm{~ms}$; from -70 to $0 \mathrm{mV})$. The insets are plots of $\left[\mathrm{Ca}^{2+}\right]$ decay rates $\left(d\left[\mathrm{Ca}^{2+}\right]_{\mathrm{i}} / d t\right)$ at the peak of each CaTs calculated from Equation 3 against the amplitudes of the $\mathrm{CaT}\left(\Delta\left[\mathrm{Ca}^{2+}\right]_{\text {peak }}\right)$. The largest $\mathrm{CaTs}$ in each set of CaTs from WT and Tg2576 are superimposed in the rightmost image. $\boldsymbol{B}$, The peak amplitudes of $\mathrm{CaTs}\left(\Delta\left[\mathrm{Ca}^{2+}\right]_{\text {peak }}\right)$ induced by a depolarizing step of various durations are shown for WT (blue circle) and $\operatorname{Tg} 2576$ (red circle). $\boldsymbol{C}$, A summary graph for $C \mathrm{Ca}^{2+}$ decay rates as a function of $\Delta\left[\mathrm{Ca}^{2+}\right]_{\text {peak. }}$. Numbers in parentheses are the numbers of neurons/mice studied. $D, \mathrm{Ca}^{2+}$ decay rate constant $\left(\lambda_{t=0}\right)$ as a function of $\Delta\left[\mathrm{Ca}^{2+}\right]_{\text {peak }} \cdot \lambda_{t=0}$ was calculated by dividing each value for $\mathrm{Ca}^{2+}$ decay rate shown in C by corresponding $\Delta\left[\mathrm{Ca}^{2+}\right]_{\text {peak }}$ according to Equation 4. $E$, Mean values for $\mathrm{Ca}^{2+}$ clearance $\left(\mathrm{C}_{\mathrm{Ca}^{2}}\right.$ ) obtained from WT (blue) and Tg2576 (red). $C_{\mathrm{Ca}}$ is defined as the $\lambda_{t=0}$ value at $\Delta\left[\mathrm{Ca}^{2+}\right]_{\text {peak }}>0.8 \mu \mathrm{m}$, and typically estimated from a CaT evoked by a 200 ms step pulse. $n$, number of cells tested. Mean \pm SEM. ${ }^{* *} p<0.01$.

we obtained a $\mathrm{Ca}^{2+}$-decay rate constant at the peak of a $\mathrm{CaT}\left(\lambda_{t=0}\right)$ as follows:

$$
\lambda_{t=0} \equiv r_{t=0} / \Delta\left[\mathrm{Ca}^{2+}\right]_{\text {peak }}=\left(A_{1} \cdot r_{1}+A_{2} \cdot r_{2}\right) /\left(A_{1}+A_{2}\right) .
$$

Previously, we demonstrated that this term is relatively constant when $\Delta\left[\mathrm{Ca}^{2+}\right]_{\text {peak }}$ is $>0.8 \mu \mathrm{M}$ (Lee et al., 2009). Therefore, we used $\lambda_{t}=0$ obtained from the CaTs that have an amplitude within the range of $0.8-1.2 \mu \mathrm{M}$ as a parameter for representing $\mathrm{Ca}^{2+}$ clearance of a cell, and used this term for the statistical analysis. The difference between the $\mathrm{Ca}^{2+}$ clearance under control conditions and that in the presence of an inhibitor of $X$ was regarded as the contribution made by $X$. Since $\mathrm{Li}^{+}$enhances GABAergic activity in dentate GCs, choline-Cl was used as a substitute for extracellular $\mathrm{Na}^{+}$to study $\mathrm{Na}$ /Ca exchange activity. The PMCA-mediated $\mathrm{Ca}^{2+}$ clearance was calculated from the difference of thapsigargin (TG) alone and TG $+5(6)$-carboxyeosin diacetate (CE) because CE alone partially blocks SERCA in addition to PMCA inhibition.

Measurement of mitochondrial superoxide level and membrane potential. The mitochondrial superoxide levels and mitochondrial membrane potential $\left(\Delta \Psi_{\mathrm{m}}\right)$ were assessed by the fluorescence of MitoSOX Red (Invitrogen) and tetramethylrhodamine ethyl ester perchlorate (TMRE; Invitrogen), respectively. Hippocampal slices were loaded with $200 \mathrm{~nm}$ MitoSOX Red for $30 \mathrm{~min}$ or $200 \mathrm{~nm}$ TMRE for $40 \mathrm{~min}$ in the dark at $37^{\circ} \mathrm{C}$ while carbogen was continuously supplied in the bath solution. MitoSOX Red and TMRE were excited by 510 and $540 \mathrm{~nm}$ of monochromatic light, respectively. A cooled CCD camera was used to collect emission fluorescence through the $624 / 40 \mathrm{~nm}$ bandpass emission filter. Time-lapse TMRE fluorescence images were captured in every $100 \mathrm{~ms}$ with an exposure time of $20 \mathrm{~ms}$.

Statistical analysis. Data were analyzed with IgorPro (Version 4.1; Wave-Metrics) and are presented as the mean \pm SEM. $n$ indicates the number of cells. The statistical significances were evaluated using Student's $t$ test.

\section{Results}

Calcium clearance is impaired in Tg2576 granule cells

We investigated $\mathrm{Ca}^{2+}$ dynamics of the hippocampal neurons from mice aged 1-2 months by imaging the fluorescence of fura- 2 in the soma, which was introduced at a concentration of $100 \mu \mathrm{M}$ via a whole-cell patch pipette. CaTs were evoked by applying depolarizing pulses (from -70 to $0 \mathrm{mV}$ ) of various durations from 10 to $200 \mathrm{~ms}$ under voltage-clamp conditions. In GCs of the dentate gyrus, the decay kinetics of CaTs showed a significant difference between the litter-mate wild-type (WT, blue traces) and Tg2576 mice (red traces; Fig. 1). Because GCs in the same brain slice display heterogeneous stages of maturation and $\mathrm{Ca}^{2+}$ dynamics are regulated developmentally, we confined our analysis to mature GCs, which exhibit typical electrophysiological criteria: low input resistance and high threshold current for an action potential (Lee et al., 2009). Figure $1 A$ shows representative sets of CaTs recorded from a mature WT GC and a Tg2576 GC. While the resting calcium level $\left(\left[\mathrm{Ca}^{2+}\right]_{\mathrm{rest}}: \mathrm{WT}, 64.5 \pm 3.2 \mathrm{nM}\right.$; Tg2576, $72.2 \pm 2.5 \mathrm{~nm})$ and the peak amplitude of CaTs $\left(\Delta\left[\mathrm{Ca}^{2+}\right]_{\text {peak }}\right.$, Fig. $\left.1 \mathrm{~B}\right)$ are not significantly different between WT GCs and Tg2576 GCs, the decay phase of the CaTs was significantly slowed in Tg2576 GCs (Fig. 1 A). We fitted the decay phase of each CaT with a biexponential function and estimated the $\mathrm{Ca}^{2+}$ decay rate $\left(d\left[\mathrm{Ca}^{2+}\right]_{\mathrm{i}} /\left.d t\right|_{t=0}\right.$ or $\left.r_{t=0}\right)$ at the peak of each CaT according to Equation 3. Because the $\mathrm{Ca}^{2+}$ decay rate depends on the cytosolic $\mathrm{Ca}^{2+}$ level $\left(\left[\mathrm{Ca}^{2+}\right]_{\mathrm{i}}\right)$, it was plotted as a function of $\Delta\left[\mathrm{Ca}^{2+}\right]_{\text {peak }}$ (inset, Fig. 1A). The composite data obtained from WT (blue circles) and Tg2576 mice (red circles) were compared in Figure $1 C$, showing that the difference in the $\mathrm{Ca}^{2+}$ decay rate between WT GCs and Tg2576 GCs became evident in the range of 
A
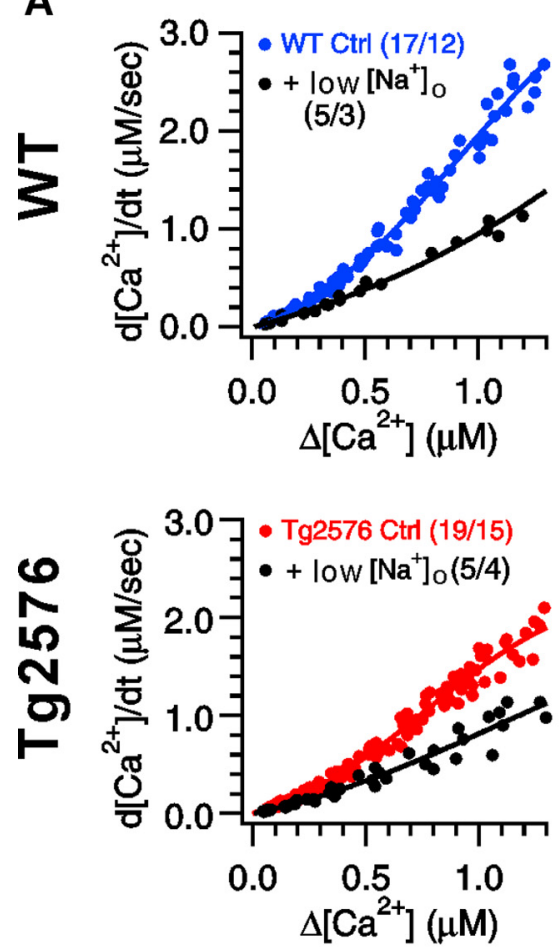

B

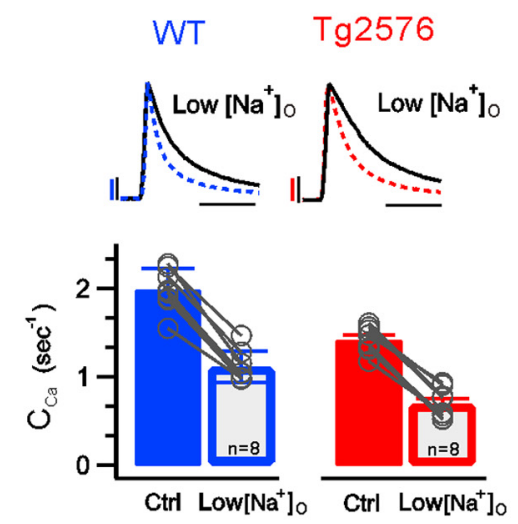

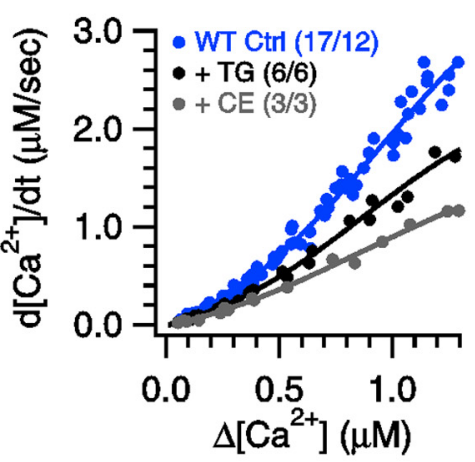

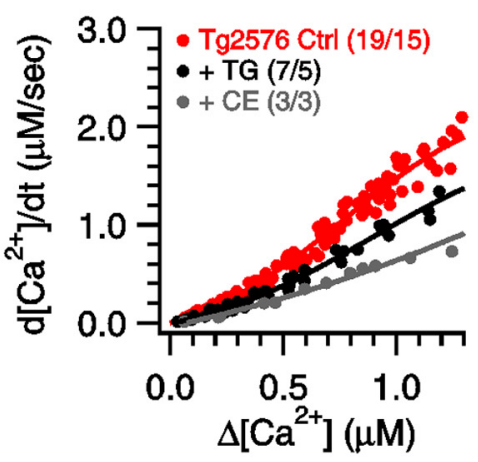

$$
\text { WT Tg2576 }
$$
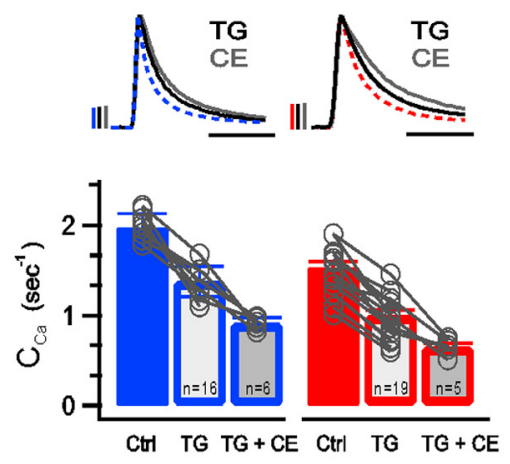
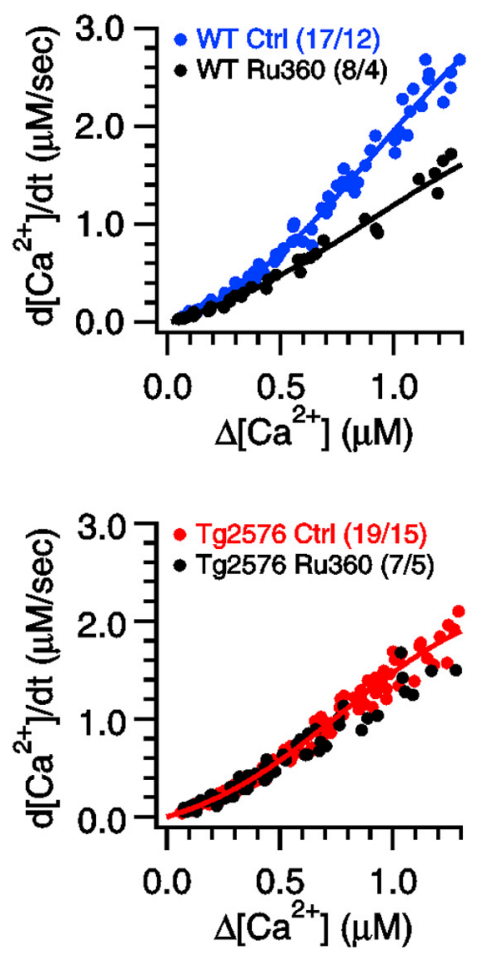

$\operatorname{Tg} 2576$
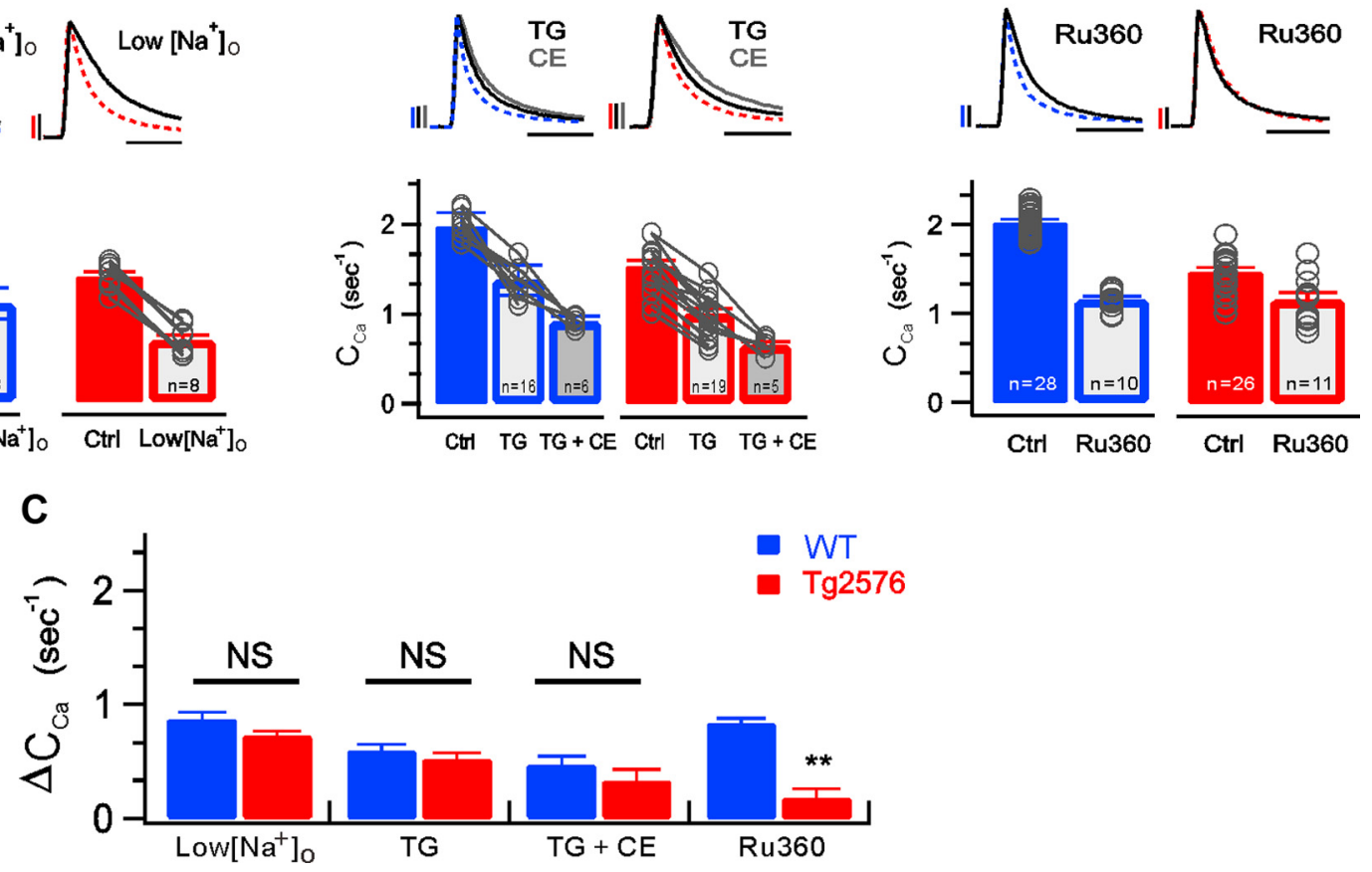

Figure 2. Contributions of specific $\mathrm{Ca}^{2+}$ clearance mechanisms in wild-type and $\mathrm{Tg} 2576 \mathrm{GCS}$. A, Analysis of $\left[\mathrm{Ca}^{2+}\right]_{\mathrm{i}}$ decay rate $\left(d\left[\mathrm{Ca}^{2+}\right]_{\mathrm{i}} / d t\right)$ before and after inhibition of specific calcium clearance mechanism. The values of $\mathrm{Ca}^{2+}$ decay rate at the peak are plotted against the corresponding $\Delta\left[\mathrm{Ca}^{2+}\right]_{\text {peak }}$ in WT (top) and Tg2576 (bottom) GCs. CaTs with various $\Delta\left[\mathrm{Ca}^{2+}\right]_{\text {peak }}$ were evoked by a depolarization pulse of various durations from 10 to $200 \mathrm{~ms}$. NCX was inhibited by lowering $\left[\mathrm{Na}^{+}\right]_{0}$ to $26 \mathrm{~mm}\left(\mathrm{low}\left[\mathrm{Na}^{+}\right]_{0}\right.$, left, black). Extracellular $125 \mathrm{~mm} \mathrm{NaCl}$ (Ctrl) was replaced with equimolar choline-Cl. SERCA pump was inhibited by pretreatment of thapsigargin (TG, $2 \mu \mathrm{m}$, middle, black). Since the PMCAinhibitor, 5(6)-carboxyeosin diacetate (CE, $40 \mu \mathrm{M})$, also partially inhibits SERCA, the additional slow-down of $\mathrm{Ca}^{2+}$ decay rate by CE in the presence of TG is attributable to PMCA activity (TG + CE, middle, gray). Mitochondrial $\mathrm{Ca}^{2+}$ uptake is inhibited by addition of $20 \mu \mathrm{m}$ Ru360 in the patch pipette (right, black). Control $\mathrm{Ca}^{2+}$ decay rates before various inhibitors are plotted in WT (top, blue) and Tg2576 mice (bottom, red). B, Representative CaTs recorded before (WT, blue dotted line; Tg2576, red broken line) and after inhibition of specific $\mathrm{Ca}^{2+}$ clearancemechanisms using low $\left[\mathrm{Na}^{+}\right]_{0}$ (left, black), TG (middle, black), $\mathrm{TG}+\mathrm{CE}$ (middle, gray) or Ru360 (right, black) in WT and Tg2576. Scale bars indicate $200 \mathrm{~nm}\left[\mathrm{Ca}^{2+}\right]_{\mathrm{i}}$ and $2 \mathrm{~s}$. Mean values for Ca ${ }^{2+}$ clearance $\left(\mathrm{C}_{\mathrm{C}_{\mathrm{a}}}\right)$ are summarized in the bar graphs on the bottom of each traces (blue bars, WT; red bars, Tg2576). Open circles indicate individual values for $\mathrm{C}_{\mathrm{Ca}^{\prime}}$ and the data obtained from the same cell before and after inhibition of specific $\mathrm{Ca}^{2+}$ clearance mechanisms are connected with lines. $C_{C}$, The decrements of $\mathrm{C}_{\mathrm{Ca}}\left(\Delta \mathrm{C}_{\mathrm{Ca}}\right)$ caused by inhibition of each $\mathrm{Ca}^{2+}$ clearance mechanism. The further decrease of $\mathrm{C}_{\mathrm{Ca}_{\mathrm{a}}}$ caused by CE in the presence of TG was denoted as "TG + CE." Because Ru360 is impermeable to the cell membrane, we compared its effect between different cells into which Ru360 or its vehicle was introduced via a whole-cell patch pipette. The mean and SE of estimates for decrement of $\mathrm{C}_{\mathrm{Ca}}$ Caused by Ru 360 was calculated from 50 bootstrap samples obtained by randomly sampling with replacement from original data $(p<0.01) . n$, the number of CaTs studied in different cells. ${ }^{* *} p<0.01$; NS, not significantly different. Error bars indicate SEM. 

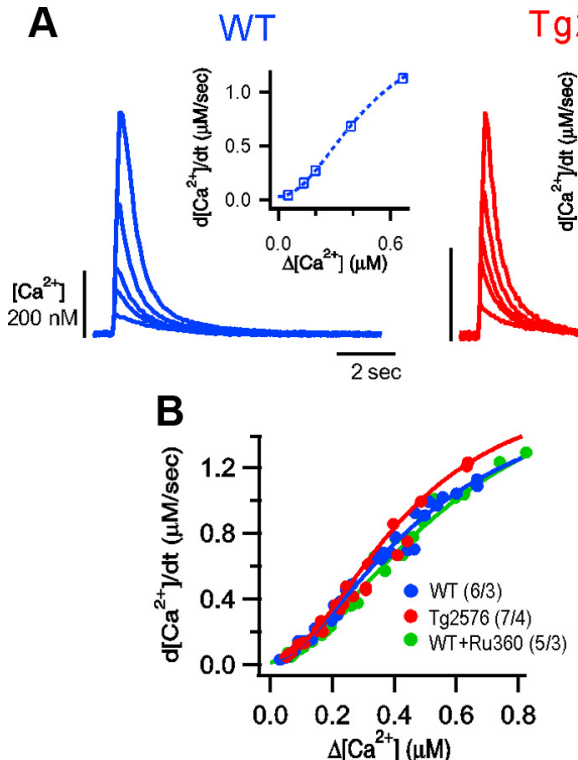

$\operatorname{Tg} 2576$

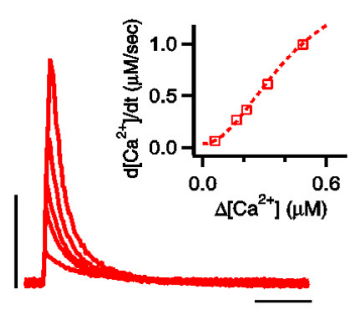

C

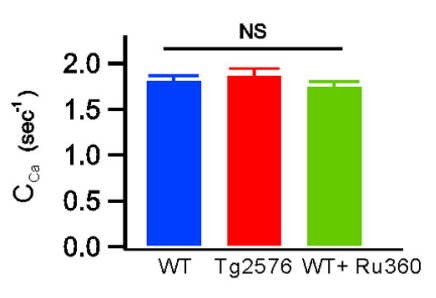

Figure 3. $\mathrm{Ca}^{2+}$ clearance in CA1 pyramidal cells of wild-type and $\mathrm{Tg} 2576$ mice. $A$, CaTs in the soma of $\mathrm{PCs}$ of CA1 hippocampus evoked by a depolarizing step pulse (from -70 to $0 \mathrm{mV}$ ) of various durations $(10,30,50,100$, and $150 \mathrm{~ms}$ ) in wild-type (WT, blue), $\operatorname{Tg} 2576$ (red), and WT + Ru360 (green). Inset, a plot of decay rates at each peak of CaTs against the corresponding $\Delta\left[\mathrm{Ca}^{2+}\right]_{\text {peak }}$. $B$, A summary graph for $\mathrm{Ca}^{2+}$ decay rates as a function of $\Delta\left[\mathrm{Ca}^{2+}\right]_{\text {peak }}$. Numbers in parentheses are the numbers of neurons/mice studied. $C, \mathrm{Ca}^{2+}$ clearance $\left(\mathrm{C}_{\mathrm{Ca}}\right)$ as a function of $\Delta\left[\mathrm{Ca}^{2+}\right]_{\text {peak }}$. NS, not significantly different. Error bars indicate SEM.

$\Delta\left[\mathrm{Ca}^{2+}\right]_{\text {peak }}>0.5 \mu \mathrm{M}$. We obtained the $\mathrm{Ca}^{2+}$ decay rate constant $\left(\lambda_{t=0}\right)$ by normalizing the $\mathrm{Ca}^{2+}$ decay rate to its peak amplitude (Eq. 4) and plotted it against $\Delta\left[\mathrm{Ca}^{2+}\right]_{\text {peak }}$ (Fig. 1D). Values for $\lambda_{t}{ }_{0}$ increased as $\left[\mathrm{Ca}^{2+}\right]_{\mathrm{i}}$ increased at a low range of $\Delta\left[\mathrm{Ca}^{2+}\right]_{\text {peak }}$, but became fairly independent of the $\Delta\left[\mathrm{Ca}^{2+}\right]_{\text {peak }}$ when the $\Delta\left[\mathrm{Ca}^{2+}\right]_{\text {peak }}$ was $>0.8 \mu \mathrm{M}$ (Fig. $1 D$ ). Since CaTs evoked by a $200 \mathrm{~ms}$ depolarizing pulse were $>0.8 \mu \mathrm{M}$, we defined " $\mathrm{Ca}^{2+}$ clearance $\left(\mathrm{C}_{\mathrm{Ca}}\right)$ " as the $\lambda_{t}=0$ value obtained from CaTs evoked by a $200 \mathrm{~ms}$ depolarizing pulse, and used this term for the statistical analysis. The mean value for $\mathrm{C}_{\mathrm{Ca}}$ was significantly lower in the Tg2576 GCs $\left(1.407 \pm 0.027 \mathrm{~s}^{-1}\right.$, $n=36)$ than in the WT GCs $\left(2.035 \pm 0.028 \mathrm{~s}^{-1}, n=29, p<\right.$ 0.01 ; Fig. $1 E$ ), indicating that the impairment of $\mathrm{Ca}^{2+}$ clearance is the earliest sign of $\mathrm{Ca}^{2+}$ dysregulation ever shown in Tg2576 mice.

\section{Mitochondrial dysfunction underlies the impaired $\mathrm{Ca}^{2+}$ clearance in the Tg2576 GCs}

The $\mathrm{Ca}^{2+}$ clearance of GCs is attributable to $\mathrm{Na} / \mathrm{Ca}$ exchanger (NCX), sarcoendoplasmic reticulum $\mathrm{Ca}^{2+}$-ATPase (SERCA), plasma membrane $\mathrm{Ca}^{2+}$-ATPase (PMCA), and mitochondria (Lee et al., 2009). To understand which $\mathrm{Ca}^{2+}$ clearance mechanisms are impaired in the Tg2576 mice, we estimated the contributions of each mechanism to the decay phase of CaTs by comparing $\mathrm{Ca}^{2+}$ clearance before and after inhibition of a given mechanism (Fig. 2). To inhibit the forward mode of NCX, extracellular $\mathrm{Na}^{+}$concentration $\left(\left[\mathrm{Na}^{+}\right]_{\mathrm{o}}\right)$ was reduced to $26 \mathrm{~mm}$ by replacing $125 \mathrm{~mm} \mathrm{NaCl}$ with equimolar choline-Cl. Under this condition, resting $\left[\mathrm{Ca}^{2+}\right]_{\mathrm{i}}$ and $\Delta\left[\mathrm{Ca}^{2+}\right]_{\text {peak }}$ were unchanged, confirming that $\mathrm{Ca}^{2+}$ influx through the reverse mode of NCX was not activated. SERCA and mitochondrial $\mathrm{Ca}^{2+}$ uptake were inhibited by thapsigargin (TG, $2 \mu \mathrm{M})$ and Ru360 $(20 \mu \mathrm{M})$, respectively. The role of PMCA in $\mathrm{Ca}^{2+}$ clearance was assessed using 5(6)-carboxyeosin diacetate (CE, $40 \mu \mathrm{M})$. Because CE can partially inhibit SERCA, we assessed the effects of CE in slices pretreated with TG for $10 \mathrm{~min}$. We analyzed $d\left[\mathrm{Ca}^{2+}\right]_{\mathrm{i}} /\left.d t\right|_{t=0}$ at
WT GCs. However, the effect of Ru360 on $\mathrm{Ca}^{2+}$ clearance was negligible in the Tg2576 GCs, indicating that the contribution of mitochondria was significantly lower in Tg2576 GCs (Fig. 2C). These results indicate that the function of mitochondrial $\mathrm{Ca}^{2+}$ uptake is selectively impaired in the $\mathrm{Tg} 2576 \mathrm{GCs}$, resulting in the reduced $\mathrm{Ca}^{2+}$ clearance.

The hippocampus is subdivided into three main regions: the dentate gyrus, CA1, and CA3 fields. The principal cells in each regions show distinctive characteristic in their electrical properties and $\mathrm{Ca}^{2+}$ dynamics. Region-specific disturbances are also reported in age-dependent changes (Burger, 2010). To examine whether selective impairment of mitochondrial $\mathrm{Ca}^{2+}$ uptake in $\mathrm{Tg} 2576$ is specific to GCs in dentate gyrus, we conducted the same series of experiments in CA1 pyramidal cells (PCs; Fig. 3). Unlike dentate GCs, the amplitude and the kinetics of CaTs did not show any significant differences between wild-type (WT) and Tg2576 mice in CA1 PCs (Fig. 3A). Furthermore, $\mathrm{Ca}^{2+}$ decay rate and $\mathrm{Ca}^{2+}$ clearance were unaffected by Ru360, indicating that the mitochondrial contribution to $\mathrm{Ca}^{2+}$ clearance is negligible in the CA1 PCs (Fig. $3 B, C$ ). These results support the idea that a significant contribution of mitochondria to $\mathrm{Ca}^{2+}$ clearance is a unique feature of dentate GCs, which makes GCs susceptible to mitochondrial impairment.

\section{Pretreatment with $\mathrm{A} \boldsymbol{\beta}_{1-42}$ decreases $\mathrm{Ca}^{2+}$ clearance specifically in dentate GCs}

$\mathrm{A} \beta$ is believed to be the most important pathogenic factor in $\mathrm{AD}$. Before we investigated the involvement of $\mathrm{A} \beta$ in the impairment of $\mathrm{Ca}^{2+}$ clearance in $\mathrm{Tg} 2576$ mice, we first examined whether the measurable amount of $A \beta$ is produced at the age of $\mathrm{Tg} 2576$ mice used in this study. Among various species of $\mathrm{A} \beta, \mathrm{A} \beta_{1-40}$ is most abundant and $\mathrm{A} \beta_{1-42}$ is most toxic (Mucke et al., 2000; Walsh and Selkoe, 2007). We measured the amount of $A \beta_{1-40}$ and $\mathrm{A} \beta_{1-42}$ in different regions of brain slices of the Tg2576 mice using ELISA assay (Fig. $4 C$ ). Both $\mathrm{A} \beta_{1-40}$ and $\mathrm{A} \beta_{1-42}$ were detected in cerebral cortex (Ctx) and hippocampus, with no significant difference among the different regions, except that the level 
of $\mathrm{A} \beta_{1-42}$ in the dentate gyrus (DG) was higher compared with that in other regions of the hippocampus [Hippo(-DG)] or in the cortex.

We then examined whether impairment of the $\mathrm{Ca}^{2+}$ clearance observed in the Tg2576 GCs could be mimicked by exogenous application of oligomeric $\mathrm{A} \beta_{1-42}$ or $\mathrm{A} \beta_{1-40}$ to the WT GCs. We used a relatively high concentration $(1 \mu \mathrm{M})$ to minimize the incubation time. After an hour incubation in the $\mathrm{A} \beta_{1-42}$-containing aCSF, the hippocampal slices from the WT mice exhibited slower decay phases of the CaTs than the un-treated controls (Fig. 4A) whereas the $\left[\mathrm{Ca}^{2+}\right]_{\text {rest }}$ (WT, $64.5 \pm 3.2 \mathrm{nM}$ vs $\mathrm{WT}+\mathrm{A} \beta, 74.4 \pm 3.4$ $\mathrm{nM})$ and $\Delta\left[\mathrm{Ca}^{2+}\right]_{\text {peak }}(\mathrm{WT}, 1.26 \pm 0.14$ $\mathrm{nM}$ vs $\left.\mathrm{WT}+\mathrm{A} \beta_{1-42}, 1.28 \pm 0.10 \mathrm{nM}\right)$ were not significantly different. The mean value for $\mathrm{C}_{\mathrm{Ca}}$ in $\mathrm{A} \beta_{1-42}$-treated WT GCs was $1.37 \pm 0.03 \mathrm{~s}^{-1}(n=17)$, which is significantly slower than that of untreated WT GCs $(p<0.01)$ but comparable to the value obtained from Tg2576 GCs. In contrast, pretreatment with $\mathrm{A} \beta_{1-40}$ did not affect $\mathrm{Ca}^{2+}$ clearance, supporting a key role of oligomeric $A \beta_{1-42}$ in the impaired $\mathrm{Ca}^{2+}$ clearance observed in the Tg2576 GCs.

We showed that $\mathrm{Ca}^{2+}$ clearance in CA1 PCs is not affected in Tg2576 (Fig. 3), and suggested that a negligible contribution of mitochondria to the $\mathrm{Ca}^{2+}$ clearance in CA1 PCs makes CA1 PCs not susceptible to mitochondrial impairment induced in $\mathrm{Tg} 2576$. However, it may also be possible that a lower level of $\mathrm{A} \beta_{1-42}$ in $\mathrm{CA} 1$ region is responsible for the normal $\mathrm{Ca}^{2+}$ clearance in Tg2576 CA1 pyramidal neurons. To examine this possibility, we examined the effect of exogenous $\mathrm{A} \beta_{1-42}$ on $\mathrm{Ca}^{2+}$ clearance in CA1 PCs. Unlike the effect on GCs (Fig. 4A), there was no significant effect of $\mathrm{A} \beta_{1-42}$ on $\mathrm{Ca}^{2+}$ clearance in CA1 PCs (Fig. $4 B$ ). These results support the idea that $\mathrm{A} \beta_{1-42}$ under this experimental condition specifically induces the impairment of mitochondrial $\mathrm{Ca}^{2+}$ uptake, and thus does not affect $\mathrm{Ca}^{2+}$ clearance of CA1 PCs in which mitochondrial contribution is negligible.

\section{Mitochondria in the Tg2576 GCs are under oxidative stress and become depolarized}

What is the underlying mechanism of the impaired mitochondrial $\mathrm{Ca}^{2+}$ uptake in the Tg2576 GCs? To determine whether mitochondrial dysfunction underlies the impairment of $\mathrm{Ca}^{2+}$ uptake in Tg2576, mitochondrial ROS generation and membrane potential $\left(\Delta \Psi_{\mathrm{m}}\right)$ were evaluated in the dentate GCs using MitoSOX Red and TMRE, respectively (Fig. 5). Whereas the cell morphology in DIC images was not changed, MitoSOX Red fluorescence was significantly increased in the Tg2576 GCs compared with that of the WT GCs, which is indicative of the increased mitochondrial superoxide level in the Tg2576 GCs (Fig. $5 A$ ). Furthermore, the TMRE fluorescence image indicates that the $\Delta \Psi_{\mathrm{m}}$ of the Tg2576 GCs is partially depolarized compared with that of the WT GCs (Fig. $5 B$ ). Figure $5 B b$ shows recordings of TMRE fluorescence intensity of hot spots, in-focused mitochondria, indicated by arrowheads in TMRE fluorescence images, before and after addition of $1 \mu \mathrm{M}$ carbonylcyanide $p$-trifluoromethoxyphenylhydrazone (FCCP). A hot spot is defined as a pixel, the brightness of which is higher than two SDs of the Gaussian fit to the intensity histogram of the ROI drawn over the focused GC layer. The mean FCCP-sensitive TMRE fluorescence $\left(\Delta \mathrm{F}_{\mathrm{TMRE}}\right)$ was significantly lower in the Tg2576 GCs (29 mitochondria from 5 mice) compared with that of the WT GCs ( 24 mitochondria from 3 mice; Fig. 5Bc). Interestingly, the TMRE fluorescence of the individual hot spot in the WT GCs showed a small flickering, a brief drop of the fluorescence intensity, reflecting a brief and reversible depolarization (Fig. $5 B b$, WT). Such flickering was observed previously in cultured neurons and considered to be an indication of normal mitochondrial respiratory function (Buckman and Reynolds, 2001). However, reversible fluctuations of $\Delta \mathrm{F}_{\mathrm{TMRE}}$ were rarely observed in the Tg2576 GCs. 
A

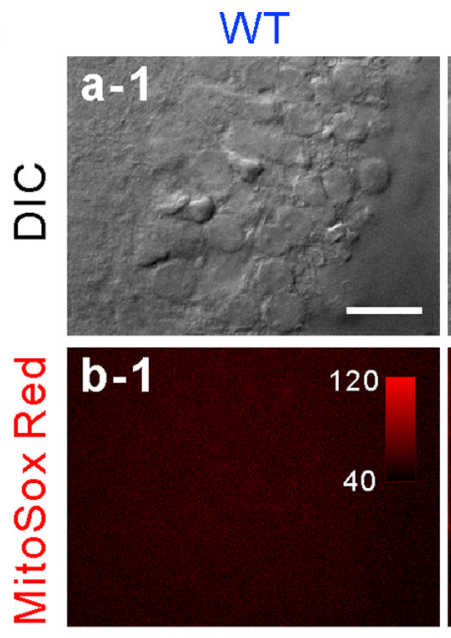

C

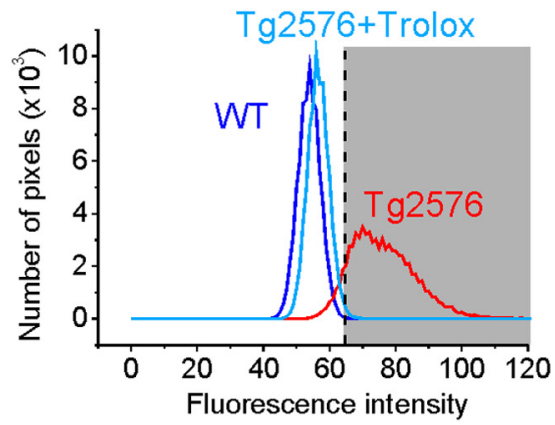

$\operatorname{Tg} 2576$
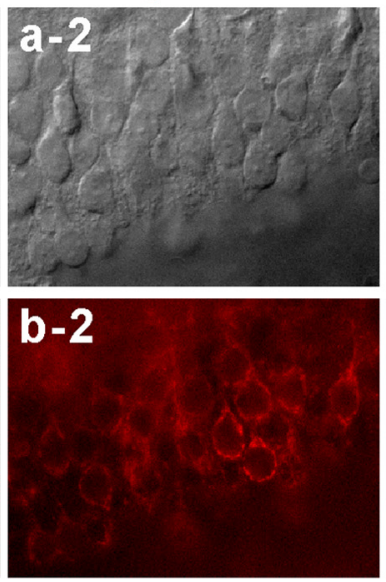

d

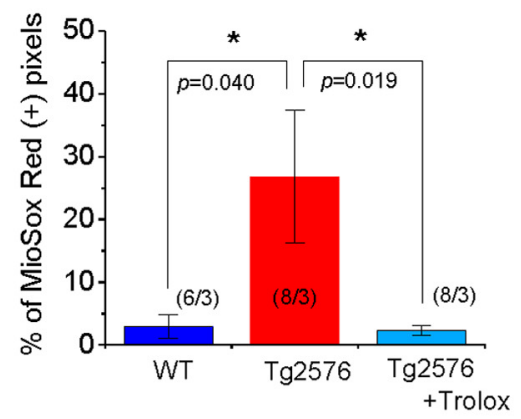

B
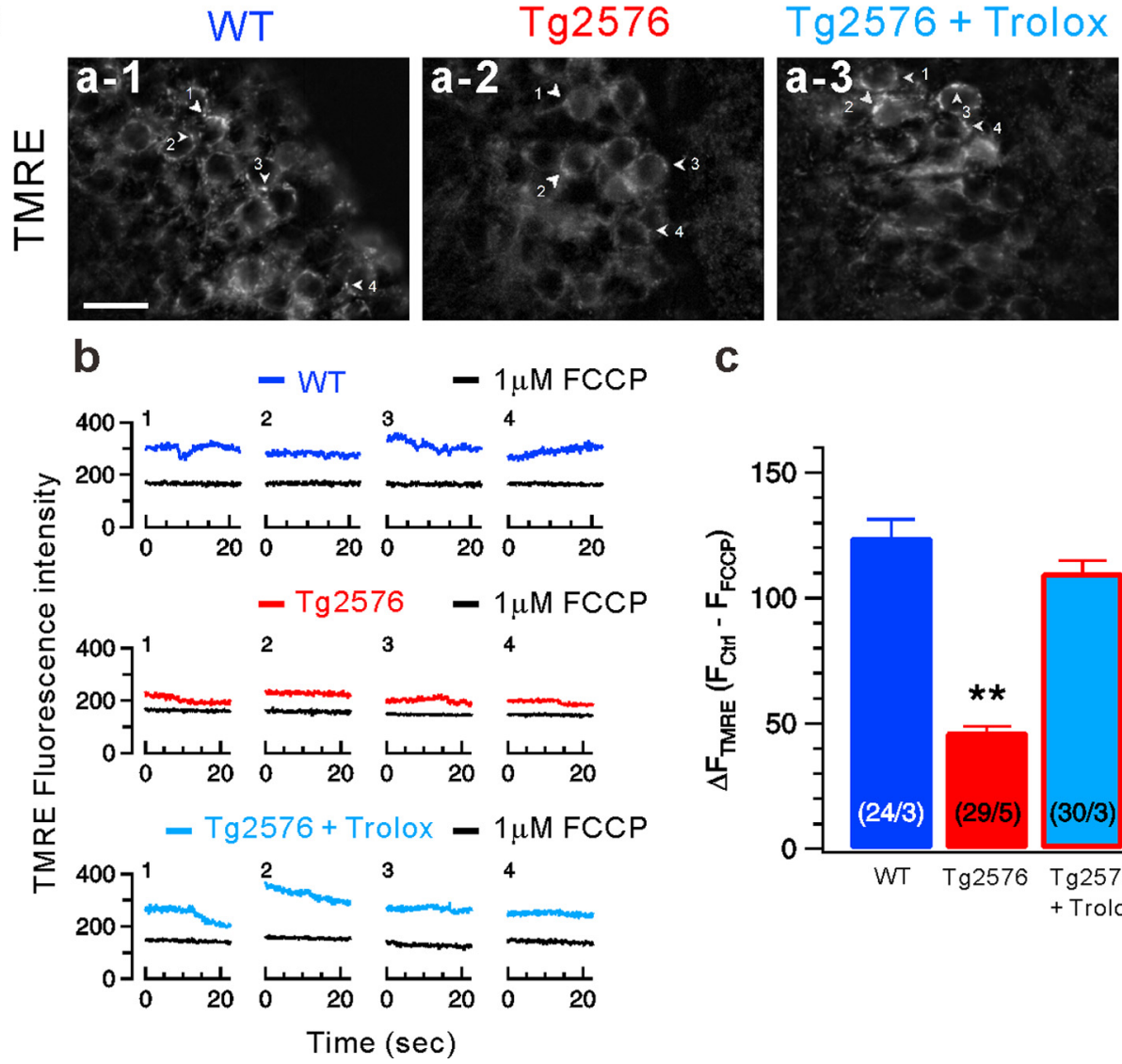

C

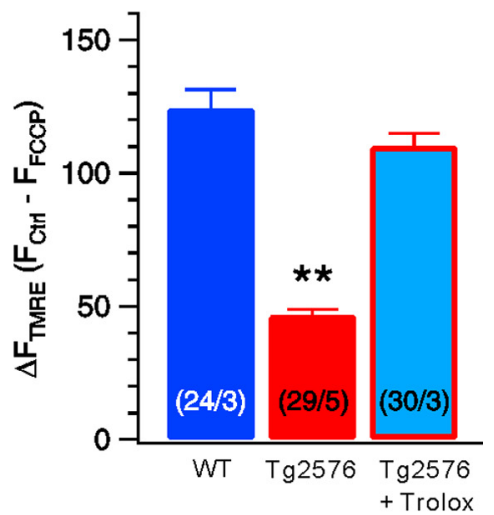

Figure 5. Mitochondrial superoxide generation ( $\boldsymbol{A})$ and mitochondrial membrane potential $\left(\Delta \Psi_{\mathrm{m}}, \boldsymbol{B}\right)$ probed by MitoSOX Red and TMRE, respectively, in wild-type and Tg2576 GCs. $\boldsymbol{A}, \mathrm{DIC}(\boldsymbol{A a})$ and MitoSOX Red (Ab) fluorescence images of the GC layer of the dentate gyrus in WT (left), Tg2576 (middle), and Tg2576 + Trolox (right). The right images were taken from Tg2576 GCs after pretreatment with $500 \mu \mathrm{m}$ Trolox for $2 \mathrm{~h}$. Ac shows fluorescence intensity histograms of the MitoSOX Red fluorescence images shown in $\boldsymbol{A} \boldsymbol{b}$ (blue, WT; red, Tg2576; (Figure legend continues.) 


\section{Mitochondrial dysfunction can be restored by antioxidant treatment}

To further determine whether the increased mitochondrial ROS generation is causally related to mitochondrial dysfunction and $\mathrm{Ca}^{2+}$ dysregulation in the Tg2576 mice, we examined whether the antioxidant, 6-Hydroxy-2,5,7,8-tetramethylchromane-2carboxylic acid (Trolox), can restore $\Delta \Psi_{\mathrm{m}}$ and $\mathrm{Ca}^{2+}$ clearance. Preincubation of the Tg2576 GCs in the aCSF containing $500 \mu \mathrm{M}$ Trolox reduced MitoSOX Red fluorescence (Fig. 5Ab-3), suggesting its effective scavenging of mitochondrial ROS. Under this condition, $\Delta \mathrm{F}_{\mathrm{TMRE}}$ was fully restored to the level of the WT GCs (Fig. 5B). Furthermore, Trolox also restored the $\mathrm{Ca}^{2+}$ clearance in the Tg2576 GCs (Fig. 6). The mean value for $\mathrm{C}_{\mathrm{Ca}}$ in the $\mathrm{Tg} 2576$ $\left(1.407 \pm 0.027 \mathrm{~s}^{-1}, n=36\right)$ was significantly increased by the Trolox treatment $\left(2.187 \pm 0.078 \mathrm{~s}^{-1}, n=9, P<0.01\right)$, becoming comparable to the value for the WT GCs $\left(2.035 \pm 0.028 \mathrm{~s}^{-1}, n=\right.$ 29 , Horizontal dotted line, Fig. $6 C$ ). To exclude the possibility that Trolox nonspecifically affects $\mathrm{Ca}^{2+}$ clearance, we confirmed that the Trolox effect in Tg2576 GCs was abolished in the presence of $\mathrm{Ru} 360$. In addition, we confirmed that Trolox did not affect $\mathrm{Ca}^{2+}$ clearance in WT GCs $\left(1.908 \pm 0.046 \mathrm{~s}^{-1}, n=3\right)$, further supporting that the Trolox effect in Tg2576 GCs is indeed attributable to rescuing mitochondrial dysfunction. Together, restoration of the $\Delta \Psi_{\mathrm{m}}$ and $\mathrm{Ca}^{2+}$ clearance by Trolox in the Tg2576 GCs is consistent with the idea that the increased mitochondrial ROS in the Tg2576 GCs is responsible for the depolarization of $\Delta \Psi_{\mathrm{m}}$ and impaired mitochondrial $\mathrm{Ca}^{2+}$ clearance.

\section{Mitochondrial dysfunction underlies the synaptic dysfunction in the Tg2576 GCs}

Previously, we reported that presynaptic mitochondrial $\mathrm{Ca}^{2+}$ uptake during HFS and subsequent post-tetanic $\mathrm{Ca}^{2+}$ release from mitochondria are responsible for presynaptic residual calcium $\left(\mathrm{Ca}_{\text {res }}\right)$ which mediates PTP at the synapses made by large terminals of MF, an axon fiber of hippocampal GCs (Lee et al., 2007a). Given that mitochondrial $\mathrm{Ca}^{2+}$ uptake is impaired in the Tg2576 GCs, we hypothesized that MF axon terminals of Tg2576 mice exhibit lower post-tetanic $\mathrm{Ca}_{\text {res }}$, and thus the MF-CA3 synapses of Tg2576 show lower PTP compared with those of the WT mice. To examine this hypothesis, we recorded the baseline EPSC amplitudes for $3 \mathrm{~min}$ at the MF-CA3 synapse, and then stimulated MFs at $25 \mathrm{~Hz}$ for $5 \mathrm{~s}$ to induce PTP. A representative time course of the change in normalized EPSC amplitudes recorded from the WT CA3-PCs is shown in Figure 7A. To assess the mitochondrial dependence of PTP, we used $2 \mu \mathrm{M}$ of tetraphenylphosphonium $\left(\mathrm{TPP}^{+}\right)$instead of Ru360, because the effect of Ru360 cannot be evaluated in the same synapse due to its low permeability. $\mathrm{TPP}^{+}$is well permeable through the cell membrane and specifically inhibits post-tetanic mitochondrial $\mathrm{Ca}^{2+}$ release

\section{$\leftarrow$}

(Figure legend continued.) light blue, Tg2576 + Trolox). A MitoSOX Red-positive pixel is defined as a pixel whose fluorescence intensity is higher than two SD of the control intensity profile (indicated by the vertical dashed line and shaded area on $\boldsymbol{A c}$ ). Ad summarizes the proportion of MitoSox Red-positive pixels in individual MitoSox Red images. The numbers in parentheses indicate the numbers of brain slice images/mice studied under each condition. $\boldsymbol{B a}$, TMRE fluorescence images of dentate gyrus GCs from WT (left), Tg2576 (middle), and Tg2576+Trolox (right). $\boldsymbol{B} \boldsymbol{b}$, Representative traces of TMRE fluorescence measured at hot spots, in-focused mitochondria indicated by arrows in the TMRE images ( $\boldsymbol{B} \boldsymbol{a})$ from the GCs of WT (blue), $\operatorname{Tg} 2576$ (red), and Tg2576 + Trolox (light blue). Black traces are TMRE intensities after addition of $1 \mu \mathrm{M}$ FCCP. BC, Summary bar graph for the mean FCCP-sensitive TMRE fluorescence $\left(\Delta \mathrm{F}_{\text {TMRE }}\right)$. The numbers in parentheses are the numbers of hot spots/mice studied under each condition. Scale bars: $20 \mu \mathrm{m} ;{ }^{*} p<0.05 ;{ }^{* *} p<0.01$. Error bars indicate SEM.
(Lee et al., 2007a, 2008). Consistent with our previous reports, PTP of EPSCs induced in the WT CA3-PCs was substantially reduced by $2 \mu \mathrm{M} \mathrm{TPP}{ }^{+}$, whereas $\mathrm{TPP}^{+}$had no significant effect on the baseline EPSC amplitude, indicating a mitochondrial contribution to PTP at the MF-CA3 synapses (Fig. 7A). When PTP was induced by the same protocol at MF-CA3 synapses of the Tg2576 mice, it was significantly reduced, so that the mean magnitude of PTP under the control conditions in the Tg2576 mice was similar to that in the WT mice in the presence of TPP ${ }^{+}$(Fig. $7 B)$. Furthermore, PTP at the MF-CA3 synapses in the Tg2576 mice was hardly affected by $\mathrm{TPP}^{+}$(Fig. $7 B$ ), indicating that the contribution of mitochondria-dependent $\mathrm{Ca}_{\text {res }}$ to PTP is negligible in the Tg2576 mice. These results are consistent with the hypothesis that impaired mitochondrial $\mathrm{Ca}^{2+}$ uptake in the Tg2576 GCs leads to the reduction of post-tetanic mitochondrial $\mathrm{Ca}^{2+}$ release, which is a key mechanism for PTP at the MF-CA3 synapses. Finally, we examined the effect of Trolox that restored mitochondrial $\mathrm{Ca}^{2+}$ uptake. After $2 \mathrm{~h}$ of treatment with Trolox $(500 \mu \mathrm{M})$, PTP of MF-CA3 synapse of Tg2576 was restored to the level comparable to that in the WT mice and regained its sensitivity to $\mathrm{TPP}^{+}$(Fig. 7C). The magnitude of PTP was quantified as the average of the first three post-tetanic EPSC amplitudes normalized to the mean baseline amplitudes, and is summarized in Figure $7 D$. Whereas Trolox did not affect PTP and its sensitivity to $\mathrm{TPP}^{+}$in the WT MF synapse (Fig. $7 D$, squares), it restored the mitochondrial contribution to PTP at the MF-CA3 synapses of Tg2576 mice. These results imply that the restoration of PTP by Trolox can be attributed to reduced ROS and consequent restoration of $\Delta \Psi_{\mathrm{m}}$ and $\mathrm{Ca}^{2+}$ uptake. In contrast to the significant impairment of PTP at the MF-CA3 synapses in the Tg2576 mice, paired pulse ratios obtained at varying intervals $(10,30,50,100$, and $200 \mathrm{~ms}$ ) showed no significant difference (Fig. 7E), suggesting that paired pulse facilitation is not affected by mitochondrial dysfunction. These results support that PTP in the MF-CA3 synapse depends on mitochondrial $\mathrm{Ca}^{2+}$ handling and is selectively impaired in the early preclinical stage of AD.

\section{Discussion}

In the present study, using 1- to 2-month-old APP transgenic mice that overproduce $A \beta$, we discovered that mitochondrial dysfunctions, which include increased ROS production, partial depolarization of $\Delta \Psi_{\mathrm{m}}$ and impaired $\mathrm{Ca}^{2+}$ uptake, occur very early in dentate GCs, much earlier than any other functional or morphological changes known so far. Furthermore, we found that PTP in the MF-CA3 synapse was impaired, consistent with the notion that PTP is dependent on $\mathrm{Ca}_{\text {res }}$ originating from mitochondria (Lee et al., 2007a). The observation that antioxidant treatment can restore the short-term plasticity and mitochondrial $\mathrm{Ca}^{2+}$ uptake compromised in the transgenic mice suggests that the increased ROS production in mitochondria is initiating the other dysfunctions. Our study, for the first time, unravels the causal relationships between mitochondrial dysfunction and impaired short-term plasticity in early $\mathrm{AD}$ pathogenesis.

Previous studies on $\mathrm{A} \beta$-induced $\mathrm{Ca}^{2+}$ dysregulation have mainly focused on the mechanisms of how $A \beta$ induces an increase of $\left[\mathrm{Ca}^{2+}\right]_{\mathrm{i}}$ (Arispe et al., 1993; Quist et al., 2005). To identify subtle alterations in $\mathrm{Ca}^{2+}$ homeostasis, we focused on changes in $\mathrm{Ca}^{2+}$ clearance mechanisms (CCMs). Employing a method for quantitative analysis of CCMs that we established in previous studies (Lee et al., 2007b, 2009), we discovered that, in the mature GCs from the hippocampus of 1- to 2-month-old Tg2576 mice, somatic $\mathrm{Ca}^{2+}$ clearance was decreased by $25 \%$, and this decrease is attributable to the selective impairment of mito- 


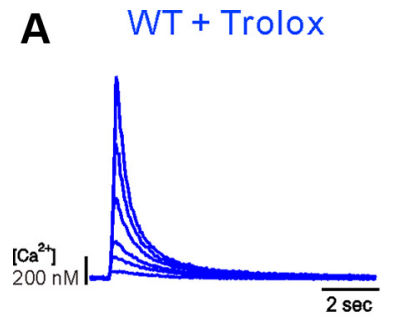

B

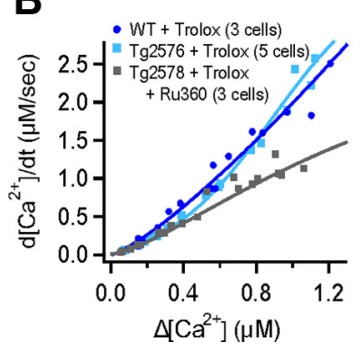

Tg2576 + Trolox

$$
\begin{aligned}
\text { Tg2576 }+ & \text { Trolox } \\
& + \text { Ru360 }
\end{aligned}
$$
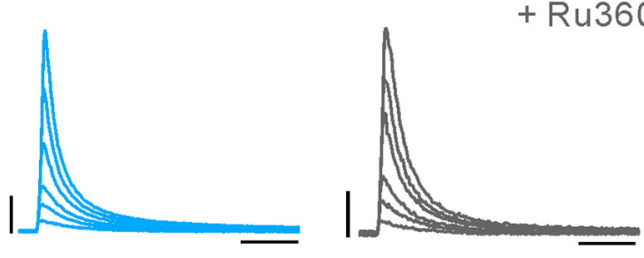

C

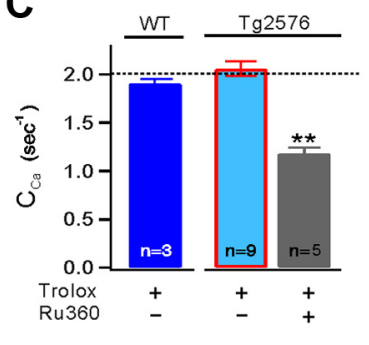

Figure 6. Effects of pretreatment with Trolox on $\mathrm{Ca}^{2+}$ clearance in $\mathrm{GCs}$ from wild-type and $\mathrm{Tg} 2576$ mice. $\boldsymbol{A}$, The $\mathrm{CaT}$ in the soma of a GC from WT (left) and Tg2576 (middle) mice after pretreatment with Trolox (500 $\mu \mathrm{m}$ for $2 \mathrm{~h}$ ). Right, The CaTs show the effects of Ru360 on the latter. CaTs were evoked by a depolarizing step pulse of various durations. $\boldsymbol{B}$, A summary graph for $\mathrm{CA}^{2+}$ decay rates as a function of $\Delta\left[\mathrm{Ca}^{2+}\right]_{\text {peak }}$ from GCS of WT + Trolox (blue), TG + Trolox (light blue), and TG + Trolox + Ru360 (gray). C, Mean values for Ca ${ }^{2+}$ clearance $\left(C_{C_{a}}\right)$ in each condition. The horizontal dotted line represents the mean value of $\mathrm{Ca}^{2+}$ clearance in the WT GCs. Scale bars: $2 \mathrm{~s}$ and $200 \mathrm{~nm}$; ${ }^{*} p<0.01 ; n$, number of cells. Error bars indicate SEM.
A
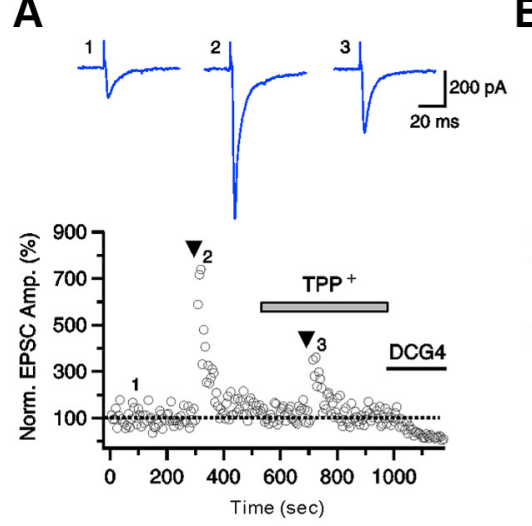

C
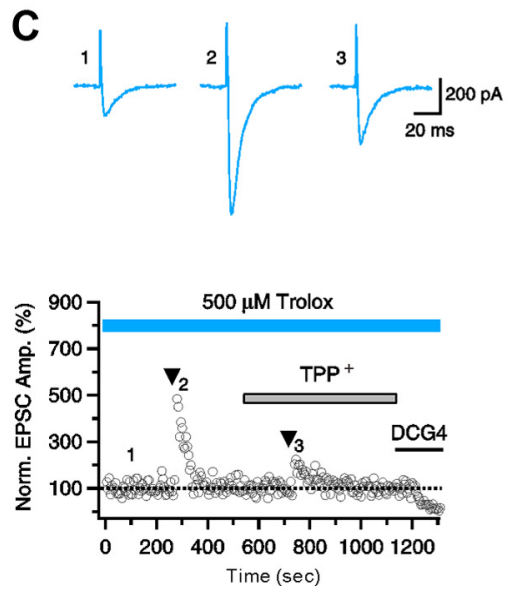

B
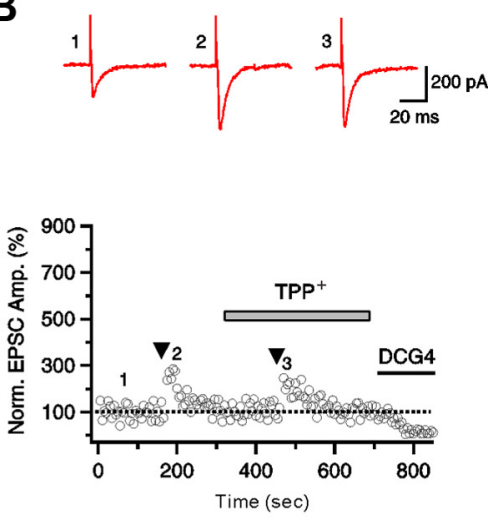

D

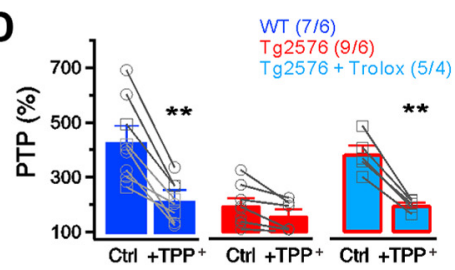

$\mathbf{E}$

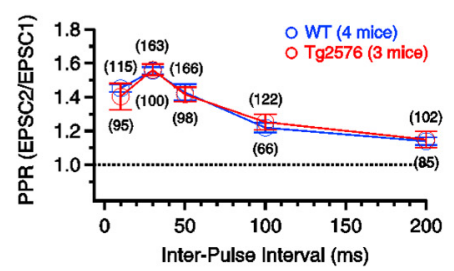

Figure 7. Impaired mitochondrial $\mathrm{Ca}^{2+}$ uptake underlies the reduced PTP at the mossy fiber synapses of the Tg2576 mice. Post-tetanic potentiation was induced by HFS $(25 \mathrm{~Hz}, 5 \mathrm{~s})$ at the MF synapses onto the CA3PCsin both the WT and Tg2576 mice. $\boldsymbol{A}, \boldsymbol{B}$, Representative time course of PTPand the effect of TPP ${ }^{+}$, a mitochondrial NCX inhibitor, on PTP of EPSCs in the CA3-PCs of aWT $(\boldsymbol{A})$ and $\operatorname{Tg} 2576(\boldsymbol{B})$ mouse.DCG4 $(2 \mu \mathrm{M})$ was applied at the end of each experiment to confirm that MF synapses are studied. $C$, Effect of pretreatment with Trolox on PTP in the Tg2576CA3-PCs.D, A summary bar graph for the mean magnitude of PTP. ForWT MF synapses, data from control synapses (circles) and those pretreated with Trolox (500 $\mu \mathrm{m}$, squares) were pooled because they were not statistically different. The numbers in parentheses are number of neurons/mice studied in each condition. $\boldsymbol{E}$, A mean paired-pulse ratio was plotted as a function of the interpulse interval. The numbers in parentheses indicate the number of paired EPSC s pooled in each data point. ${ }^{* *} p<0.01$. Error bars indicate SEM. chondrial $\mathrm{Ca}^{2+}$ uptake without changes in the activity of other CCM. Mitochondria participate in $\mathrm{Ca}^{2+}$ clearance at higher $\Delta\left[\mathrm{Ca}^{2+}\right]$ than other CCMs (Kim et al., 2005). Consistent with this notion, we found that the resting $\left[\mathrm{Ca}^{2+}\right]_{\mathrm{i}}$ was not significantly altered in the $\mathrm{Tg} 2576$ mice at this early stage. A recent study using in vivo $\mathrm{Ca}^{2+}$ imaging also reported that basal $\mathrm{Ca}^{2+}$ levels in the neurites and spines of $\mathrm{AD}$ mice did not show any sign of $\mathrm{Ca}^{2+}$ overload before $\mathrm{A} \beta$ plaques were formed (Kuchibhotla et al., 2008). An increased basal $\mathrm{Ca}^{2+}$ level has been regarded as a sign of $\mathrm{Ca}^{2+}$ dysregulation, but it may not reflect dysfunction of CCMs, which are activated under conditions of high $\left[\mathrm{Ca}^{2+}\right]_{\mathrm{i}}$, such as during high-frequency neuronal activity. Therefore, analysis of $\mathrm{Ca}^{2+}$ clearance over a wide range of $\left[\mathrm{Ca}^{2+}\right]_{\mathrm{i}}$ levels enabled us to detect the earliest changes in $\mathrm{Ca}^{2+}$ homeostasis.

Pathogenic mechanisms of how $\mathrm{Ca}^{2+}$ overload leads to neuronal degeneration have been extensively studied. However, initial neuronal dysfunction caused by a subtle alteration of $\mathrm{Ca}^{2+}$ dynamics is largely unexplored. Given that different subcellular compartments in a neuron exhibit a varying repertoire of CCMs (Lee et al., 2007c), they might be differentially affected by alteration of a CCM. Presynaptic axon terminals undergo much higher $\left[\mathrm{Ca}^{2+}\right]$ increments during high-frequency firing, and are likely to be more vulnerable to mitochondrial dysfunction than any other neuronal compartments. Presynaptic mitochondria play an essential role in the generation of posttetanic residual $\mathrm{Ca}^{2+}\left(\mathrm{Ca}_{\text {res }}\right)$, which was shown to be a key mechanism of PTP at several central synapses including MF synapses (Lee et al., 2007a, 2008). We confirmed that PTP in MF-CA3 synapses is indeed impaired in the Tg2576 mouse brain (Fig. 7B). These results suggest that presynaptic mitochondria are impaired similar to somatic ones in the Tg2576 GCs. Importantly, synaptic mitochondrial dysfunction in $\mathrm{AD}$ pathogenesis has been recently highlighted (Gillardon et al., 2007). Synaptic mitochondria show a greater degree of age-dependent accumulation of $\mathrm{A} \beta$, and are more susceptible to $A \beta$-induced damage (Du et al., 2010).

Most of the previous studies investigating $\mathrm{A} \beta$-induced synaptic dysfunction have focused on demonstrating deficits in long-term plasticity (Selkoe, 2002). It has been reported that LTP (Walsh et al., 2002) and LTD (Shankar et al., 2008; Li et al., 2009) are altered in the hippocampal CA1 area, which may involve postsynaptic dysfunction. Recently, a causal relationship between mitochondrial ROS imbal- 
ance and $\mathrm{A} \beta$-induced impairments in hippocampal LTP has been claimed (Ma et al., 2011), highlighting the importance of mitochondrial ROS in $\mathrm{AD}$ pathogenesis. In this study, LTP impairment was measured in slices from 10- to 12-month-old APP/PS1 transgenic mice. Considering that impaired long-term plasticity was observed in the Tg2576 mice aged at least 5 months (Jacobsen et al., 2006), impairment of presynaptic mitochondriadependent PTP is likely to be the earliest synaptic dysfunction in $\mathrm{AD}$ model mice reported so far. It remains to be investigated whether presynaptic and postsynaptic mechanisms underlying short-term and long-term synaptic plasticity are independently targeted by $\mathrm{A} \beta$ or presynaptic and postsynaptic dysfunctions are causally related. This issue has been recently investigated in another AD mouse model generated by mutant presenilins (PSs), another causative molecule in $\mathrm{AD}$ pathogenesis. Using a genetic approach to inactivate PSs conditionally in either presynaptic CA3 or postsynaptic CA1 PCs of the hippocampal Schaffercollateral pathway, it was demonstrated that presynaptic but not postsynaptic deletion of PSs causes a decrease in LTP as well as short-term facilitation (Zhang et al., 2009). It was thus suggested that presynaptic dysfunction might be one of the earliest pathogenic changes that can lead to postsynaptic dysfunction. Supporting this idea, the present study shows that impairment of PTP, which reflects presynaptic dysfunction, occurs in the preclinical stage of AD. If behavioral studies to detect deficit in short-term plasticity were developed, they would be beneficial for the early detection of cognitive deficits in $\mathrm{AD}$.

The hippocampus is divided into three main fields (CA1, CA3, and the dentate gyrus), and each field displays distinctive anatomical, molecular, and biophysical properties. We showed that delayed $\mathrm{Ca}^{2+}$ clearance in young Tg2576 mice was detected in dentate GCs, but not in CA1 PCs (Fig. 1 vs Fig. 3). Several possible mechanisms for these region-specific effects can be postulated. First, dentate GCs could produce more A $\beta$. Indeed, we found that the level of $\mathrm{A} \beta_{1-42}$ was higher in the dentate gyrus compared with that in other regions of the hippocampus or in the cortex (Fig. $4 C)$. Considering that $A \beta_{1-42}$ is more toxic than other species of $\mathrm{A} \beta$ (Mucke et al., 2000; Walsh and Selkoe, 2007), higher levels of $A \beta_{1-42}$ in dentate GCs could lead to the higher susceptibility of dentate GCs in Tg2576 mice brain. A second possible mechanism is that mitochondria in dentate GCs are more susceptible to $\mathrm{A} \beta$. Finally, the mitochondrial contribution to $\mathrm{Ca}^{2+}$ clearance differs between the different regions. Indeed, we found that the mitochondrial contribution to $\mathrm{Ca}^{2+}$ clearance was negligible in the CA1 PCs when $\mathrm{Ca}^{2+}$ influx was evoked by a depolarizing pulse (Fig. 3). We do not know the reason for the greater role of mitochondria in $\mathrm{Ca}^{2+}$ dynamics in dentate GCs, but it appears to be obvious that the neurons in which mitochondrial contribution is higher can be more vulnerable to mitochondrial dysfunction, and thus to $\mathrm{A} \beta_{1-42}$. It is interesting to note that disruption of a specific gene causes a different phenotype depending on a subregion even if the genes are normally expressed in all regions of the hippocampus. In calretinin-deficient mice, induction of long-term potentiation (LTP) was selectively impaired in the dentate gyrus (Schurmans et al., 1997). A hypomorphic mutation of GluN1 caused a complete suppression of early LTP in the dentate gyrus with no effect on LTP in the CA1 region (Chen et al., 2009). Similarly, subregion-specific disturbances have also been found in age-dependent changes (Burger, 2010). Likewise, assemblies of CCMs may be specialized in distinct subregions with being differentially affected by $A \beta$ in the Tg2576 mice. Precise mecha- nisms for these region-specific effects remain to be investigated in future studies.

In conclusion, we provided the first direct evidence that mitochondrial dysfunction at the early stage of $\mathrm{AD}$ is causally related to $\mathrm{Ca}^{2+}$ dysregulation and impaired short-term plasticity. More importantly, $\mathrm{Ca}^{2+}$ dysregulation and impaired short-term plasticity could be restored by antioxidant treatment. Although we did not determine the oldest age when this reversibility can be achieved by the antioxidant treatment, it was shown that vitamin E supplementation in a Tg2576 mouse model reduced the $\mathrm{A} \beta$ level and amyloid deposition only when the supplementation was started at young ages (5 months; Sung et al., 2004). In human trials, many of the antioxidant-based therapies have not proved significantly effective for the treatment of AD; rather they showed better results for the prevention of AD (Dumont and Beal, 2011). These reports including our present findings support the idea that therapies targeting oxidative stress and mitochondria are successful when used in the very early stages of the disease, or even for prevention. The present study provides a cell biologybased rationale for early antioxidant therapy in preclinical stages of $\mathrm{AD}$.

\section{References}

Arispe N, Rojas E, Pollard HB (1993) Alzheimer disease amyloid beta protein forms calcium channels in bilayer membranes: blockade by tromethamine and aluminum. Proc Natl Acad Sci U S A 90:567-571.

Beal MF (2005) Oxidative damage as an early marker of Alzheimer's disease and mild cognitive impairment. Neurobiol Aging 26:585-586.

Bezprozvanny I, Mattson MP (2008) Neuronal calcium mishandling and the pathogenesis of Alzheimer's disease. Trends Neurosci 31:454-463.

Buckman JF, Reynolds IJ (2001) Spontaneous changes in mitochondrial membrane potential in cultured neurons. J Neurosci 21:5054-5065.

Burger C (2010) Region-specific genetic alterations in the aging hippocampus: implications for cognitive aging. Front Aging Neurosci 2:140.

Chen PE, Errington ML, Kneussel M, Chen G, Annala AJ, Rudhard YH, Rast GF, Specht CG, Tigaret CM, Nassar MA, Morris RG, Bliss TV, Schoepfer R (2009) Behavioral deficits and subregion-specific suppression of LTP in mice expressing a population of mutant NMDA receptors throughout the hippocampus. Learn Mem 16:635-644.

Cho HJ, Son SM, Jin SM, Hong HS, Shin DH, Kim SJ, Huh K, Mook-Jung I (2009) RAGE regulates BACE1 and Abeta generation via NFAT1 activation in Alzheimer's disease animal model. FASEB J 23:2639-2649.

Demuro A, Mina E, Kayed R, Milton SC, Parker I, Glabe CG (2005) Calcium dysregulation and membrane disruption as a ubiquitous neurotoxic mechanism of soluble amyloid oligomers. J Biol Chem 280:17294-17300.

Du H, Guo L, Fang F, Chen D, Sosunov AA, McKhann GM, Yan Y, Wang C, Zhang H, Molkentin JD, Gunn-Moore FJ, Vonsattel JP, Arancio O, Chen JX, Yan SD (2008) Cyclophilin D deficiency attenuates mitochondrial and neuronal perturbation and ameliorates learning and memory in Alzheimer's disease. Nat Med 14:1097-1105.

Du H, Guo L, Yan S, Sosunov AA, McKhann GM, Yan SS (2010) Early deficits in synaptic mitochondria in an Alzheimer's disease mouse model. Proc Natl Acad Sci U S A 107:18670-18675.

Dumont M, Beal MF (2011) Neuroprotective strategies involving ROS in Alzheimer disease. Free Radic Biol Med 51:1014-1026.

Gillardon F, Rist W, Kussmaul L, Vogel J, Berg M, Danzer K, Kraut N, Hengerer B (2007) Proteomic and functional alterations in brain mitochondria from Tg2576 mice occur before amyloid plaque deposition. Proteomics 7:605-616.

Hardy J, Selkoe DJ (2002) The amyloid hypothesis of Alzheimer's disease: progress and problems on the road to therapeutics. Science 297:353-356.

He L, Xue L, Xu J, McNeil BD, Bai L, Melicoff E, Adachi R, Wu LG (2009) Compound vesicle fusion increases quantal size and potentiates synaptic transmission. Nature 459:93-97.

Hong HS, Rana S, Barrigan L, Shi A, Zhang Y, Zhou F, Jin LW, Hua DH (2009) Inhibition of Alzheimer's amyloid toxicity with a tricyclic pyrone molecule in vitro and in vivo. J Neurochem 108:1097-1108.

Jacobsen JS, Wu CC, Redwine JM, Comery TA, Arias R, Bowlby M, Martone R, Morrison JH, Pangalos MN, Reinhart PH, Bloom FE (2006) Early- 
onset behavioral and synaptic deficits in a mouse model of Alzheimer's disease. Proc Natl Acad Sci U S A 103:5161-5166.

Kim MH, Korogod N, Schneggenburger R, Ho WK, Lee SH (2005) Interplay between $\mathrm{Na}+/ \mathrm{Ca} 2+$ exchangers and mitochondria in $\mathrm{Ca} 2+$ clearance at the calyx of Held. J Neurosci 25:6057-6065.

Kuchibhotla KV, Goldman ST, Lattarulo CR, Wu HY, Hyman BT, Bacskai BJ (2008) Abeta plaques lead to aberrant regulation of calcium homeostasis in vivo resulting in structural and functional disruption of neuronal networks. Neuron 59:214-225.

Lee D, Lee KH, Ho WK, Lee SH (2007a) Target cell-specific involvement of presynaptic mitochondria in post-tetanic potentiation at hippocampal mossy fiber synapses. J Neurosci 27:13603-13613.

Lee SH, Park KH, Ho WK, Lee SH (2007b) Postnatal developmental changes in $\mathrm{Ca} 2+$ homeostasis in supraoptic magnocellular neurons. Cell Calcium 41:441-450.

Lee SH, Kim MH, Lee JY, Lee SH, Lee D, Park KH, Ho WK (2007c) Na+/ $\mathrm{Ca} 2+$ exchange and $\mathrm{Ca} 2+$ homeostasis in axon terminals of mammalian central neurons. Ann N Y Acad Sci 1099:396-412.

Lee JS, Kim MH, Ho WK, Lee SH (2008) Presynaptic release probability and readily releasable pool size are regulated by two independent mechanisms during posttetanic potentiation at the calyx of Held synapse. J Neurosci 28:7945-7953.

Lee SH, Ho WK, Lee SH (2009) Characterization of somatic Ca2 + clearance mechanisms in young and mature hippocampal granule cells. Cell Calcium 45:465-473.

Li S, Hong S, Shepardson NE, Walsh DM, Shankar GM, Selkoe D (2009) Soluble oligomers of amyloid Beta protein facilitate hippocampal longterm depression by disrupting neuronal glutamate uptake. Neuron 62:788-801.

Ma T, Hoeffer CA, Wong H, Massaad CA, Zhou P, Iadecola C, Murphy MP, Pautler RG, Klann E (2011) Amyloid beta-induced impairments in hippocampal synaptic plasticity are rescued by decreasing mitochondrial superoxide. J Neurosci 31:5589-5595.

Maezawa I, Hong HS, Wu HC, Battina SK, Rana S, Iwamoto T, Radke GA, Pettersson E, Martin GM, Hua DH, Jin LW (2006) A novel tricyclic pyrone compound ameliorates cell death associated with intracellular amyloid-beta oligomeric complexes. J Neurochem 98:57-67.

Mattson MP, Cheng B, Davis D, Bryant K, Lieberburg I, Rydel RE (1992) beta-Amyloid peptides destabilize calcium homeostasis and render human cortical neurons vulnerable to excitotoxicity. J Neurosci 12:376-389.

Moreira PI, Carvalho C, Zhu X, Smith MA, Perry G (2010) Mitochondrial dysfunction is a trigger of Alzheimer's disease pathophysiology. Biochim Biophys Acta 1802:2-10.

Mucke L, Masliah E, Yu GQ, Mallory M, Rockenstein EM, Tatsuno G, Hu K, Kholodenko D, Johnson-Wood K, McConlogue L (2000) High-level neuronal expression of abeta 1-42 in wild-type human amyloid protein precursor transgenic mice: synaptotoxicity without plaque formation. J Neurosci 20:4050-4058.

Palop JJ, Chin J, Roberson ED, Wang J, Thwin MT, Bien-Ly N, Yoo J, Ho KO, Yu GQ, Kreitzer A, Finkbeiner S, Noebels JL, Mucke L (2007) Aberrant excitatory neuronal activity and compensatory remodeling of inhibitory hippocampal circuits in mouse models of Alzheimer's disease. Neuron 55:697-711.

Quist A, Doudevski I, Lin H, Azimova R, Ng D, Frangione B, Kagan B, Ghiso J, Lal R (2005) Amyloid ion channels: a common structural link for protein-misfolding disease. Proc Natl Acad Sci U S A 102:10427-10432.

Schurmans S, Schiffmann SN, Gurden H, Lemaire M, Lipp HP, Schwam V, Pochet R, Imperato A, Böhme GA, Parmentier M (1997) Impaired longterm potentiation induction in dentate gyrus of calretinin-deficient mice. Proc Natl Acad Sci U S A 94:10415-10420.

Selkoe DJ (2002) Alzheimer's disease is a synaptic failure. Science 298: 789-791.

Shankar GM, Li S, Mehta TH, Garcia-Munoz A, Shepardson NE, Smith I, Brett FM, Farrell MA, Rowan MJ, Lemere CA, Regan CM, Walsh DM, Sabatini BL, Selkoe DJ (2008) Amyloid-beta protein dimers isolated directly from Alzheimer's brains impair synaptic plasticity and memory. Nat Med 14:837-842.

Smith MA, Perry G, Richey PL, Sayre LM, Anderson VE, Beal MF, Kowall N (1996) Oxidative damage in Alzheimer's. Nature 382:120-121.

Sung S, Yao Y, Uryu K, Yang H, Lee VM, Trojanowski JQ, Praticò D (2004) Early vitamin E supplementation in young but not aged mice reduces Abeta levels and amyloid deposition in a transgenic model of Alzheimer's disease. FASEB J 18:323-325.

Tanzi RE, Bertram L (2005) Twenty years of the Alzheimer's disease amyloid hypothesis: a genetic perspective. Cell 120:545-555.

Tu H, Nelson O, Bezprozvanny A, Wang Z, Lee SF, Hao YH, Serneels L, De Strooper B, Yu G, Bezprozvanny I (2006) Presenilins form ER Ca2+ leak channels, a function disrupted by familial Alzheimer's disease-linked mutations. Cell 126:981-993.

Walsh DM, Selkoe DJ (2007) A beta oligomers-a decade of discovery. J Neurochem 101:1172-1184.

Walsh DM, Klyubin I, Fadeeva JV, Cullen WK, Anwyl R, Wolfe MS, Rowan MJ, Selkoe DJ (2002) Naturally secreted oligomers of amyloid beta protein potently inhibit hippocampal long-term potentiation in vivo [Letter]. Nature 416:535-539.

Witton J, Brown JT, Jones MW, Randall AD (2010) Altered synaptic plasticity in the mossy fibre pathway of transgenic mice expressing mutant amyloid precursor protein. Mol Brain 3:32.

Zhang C, Wu B, Beglopoulos V, Wines-Samuelson M, Zhang D, Dragatsis I, Südhof TC, Shen J (2009) Presenilins are essential for regulating neurotransmitter release. Nature 460:632-636. 